\title{
Molten Salts for High Temperature Reactors: University of Wisconsin Molten Salt Corrosion and Flow Loop Experiments - Issues Identified and Path Forward
}

Piyush Sabharwall

Matt Ebner

Manohar Sohal

Phil Sharpe

Mark Anderson

Kumar Sridharan James Ambrosek Luke Olson

Paul Brooks

March 2010
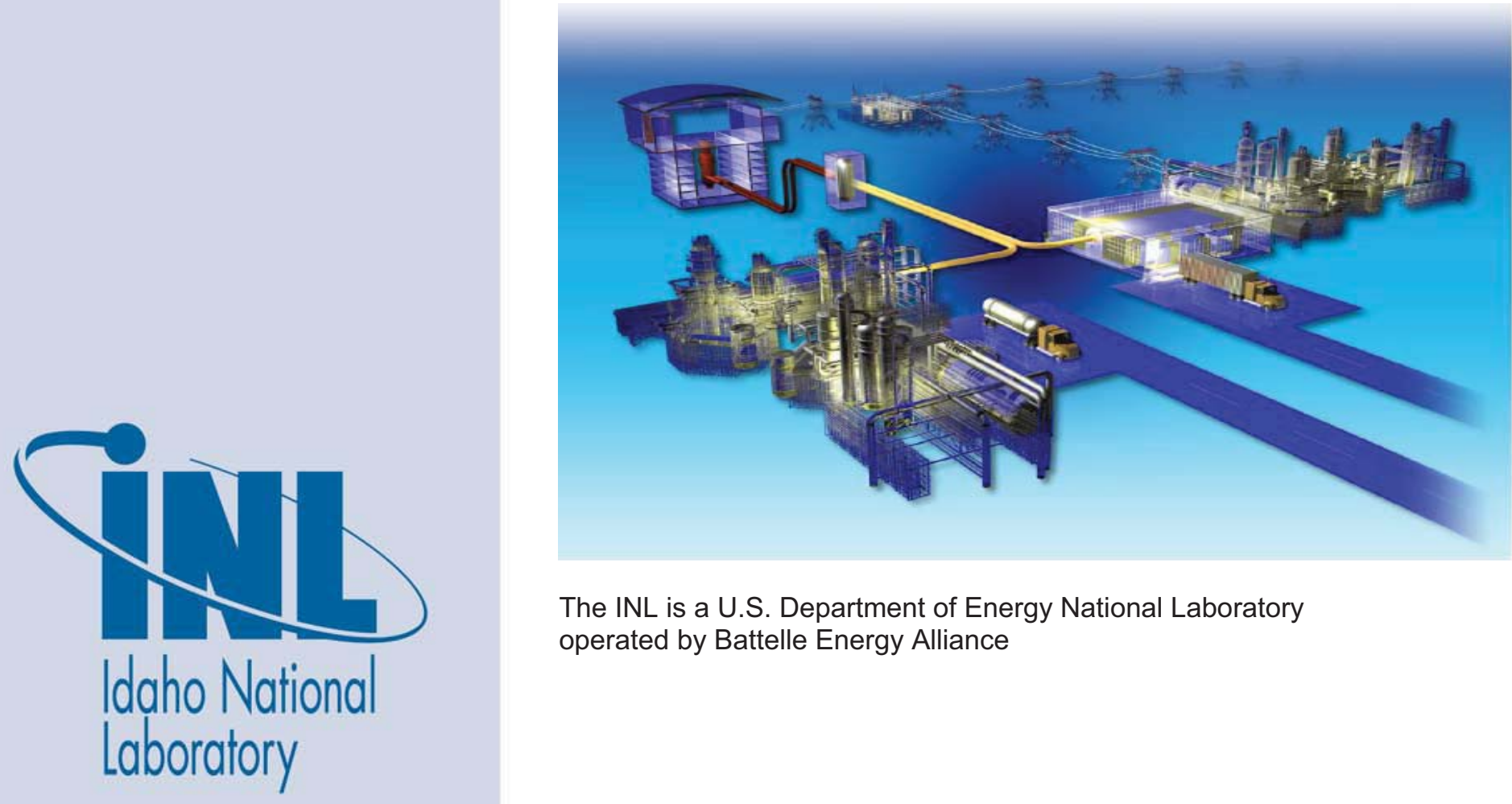

The INL is a U.S. Department of Energy National Laboratory operated by Battelle Energy Alliance 
INL/EXT-10-18090

\section{Molten Salts for High Temperature Reactors: University of Wisconsin Molten Salt Corrosion and Flow Loop Experiments - Issues Identified and Path Forward}

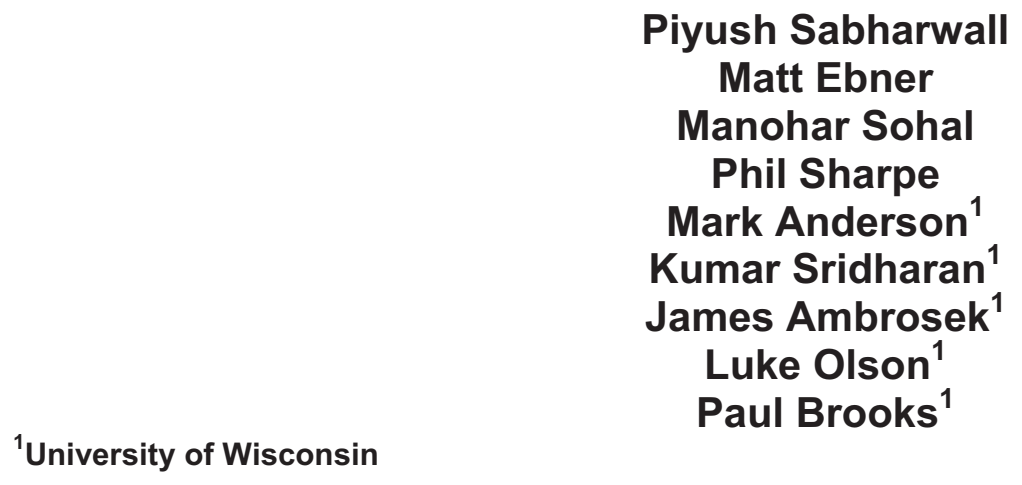

March 2010

Idaho National Laboratory

Idaho Falls, Idaho 83415

http://www.inl.gov

Prepared for the

U.S. Department of Energy

Office of Nuclear Energy

Under DOE Idaho Operations Office

Contract DE-AC07-05ID14517 


\section{DISCLAIMER}

This information was prepared as an account of work sponsored by an agency of the U. S. Government. Neither the U. S. Government nor any agency thereof, nor any of their employees, makes any warranty, expressed or implied, or assumes any legal liability or responsibility for the accuracy, completeness, or usefulness, of any information, apparatus, product, or process disclosed, or represents that its use would not infringe privately owned rights. References herein to any specific commercial product, process, or service by trade name, trade mark, manufacturer, or otherwise, does not necessarily constitute or imply its endorsement, recommendation, or favoring by the U. S. Government or any agency thereof. The views and opinions of authors expressed herein do not necessarily state or reflect those of the U. S. Government or any agency thereof. 



\title{
Molten Salts for High Temperature Reactor: University of Wisconsin Molten Salt Corrosion and Flow Loop Experiments - Issues Identified and Path Forward
}

\author{
INL/EXT-10-18090
}

March 2010

Approved by:

Phil Sharpe

Date

Project Manager, Thermal Science and Safety Analysis 



\begin{abstract}
Considerable work is being done on the development of high temperature liquid salts technology to meet the future process needs of the Next Generation Nuclear Plant. This report identifies the important characteristics and concerns of high temperature molten salts (based on University of Wisconsin-Madison's Molten Salt Research Program) and provides recommendations for future work in this important area.
\end{abstract}




\section{CONTENTS}

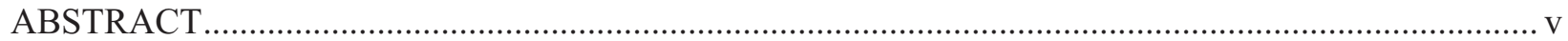

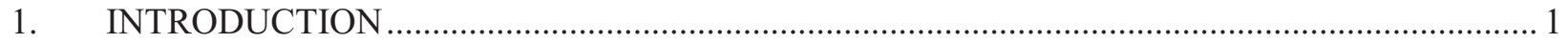

2. MOLTEN SALTS AS POTENTIAL HEAT TRANSFER COOLANT ........................................ 3

3. UNIVERSITY OF WISCONSIN - MADISON MOLTEN SALT EXPERIMENTS AND

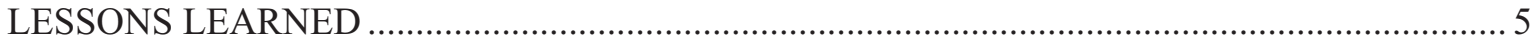

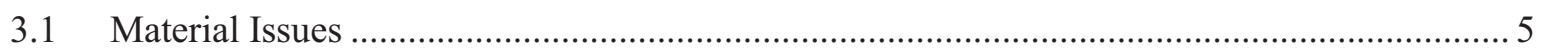

3.1.1 General Corrosion Behavior and Trends................................................................ 5

3.1.2 Container Material Influence on Corrosion ................................................................ 7

3.1.3 Material Rankings as Measure of Corrosion (with FLiNaK) .................................... 9

3.1.4 Measure of Corrosion (with $\mathrm{KCl}-\mathrm{MgCl}_{2}$ ) ..................................................... 9

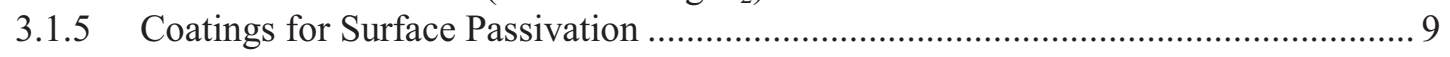

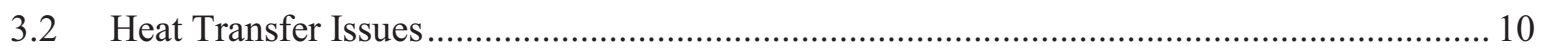

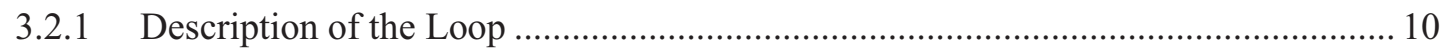

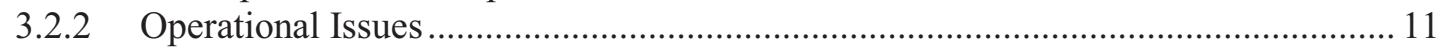

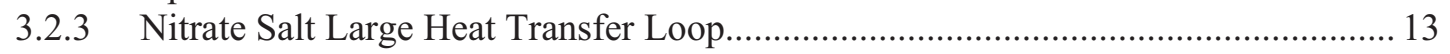

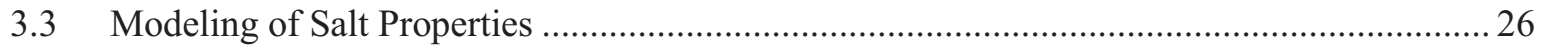

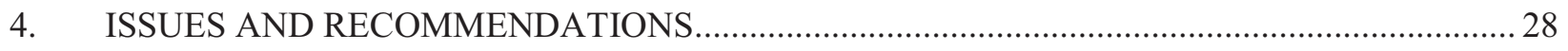

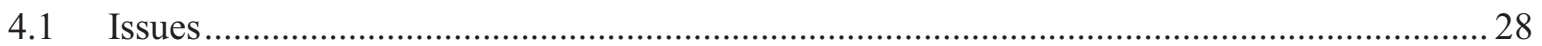

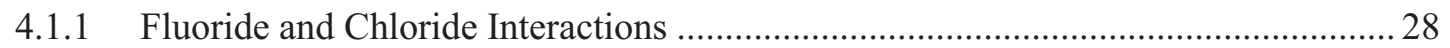

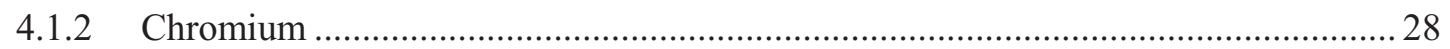

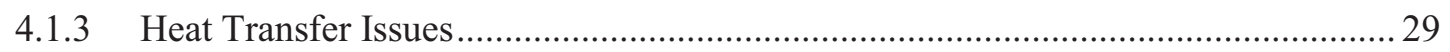

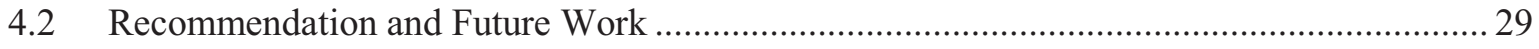

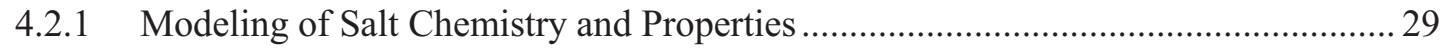

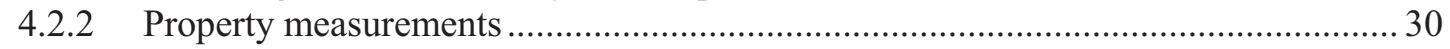

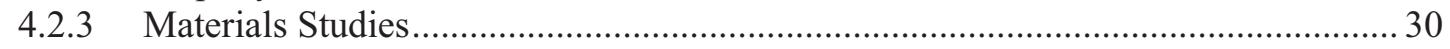

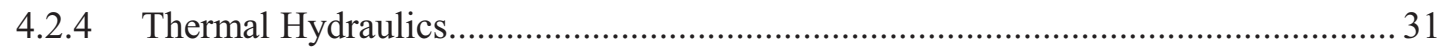

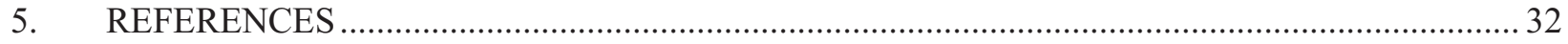

\section{FIGURES}

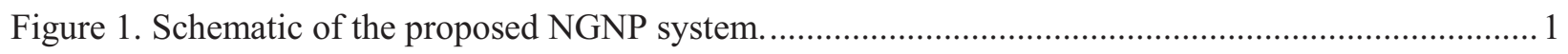

Figure 2. Gibbs free energy of fluoride formation per $\mathrm{F}_{2}$ molecule of various metals present in the salt and materials at $1,027^{\circ} \mathrm{C}$.

Figure 3. (A) The weight loss per area approximately correlates to the initial alloy chromium content. (B) Correlation between chromium in the salt after corrosion tests and the initial chromium content of the alloy. (C) Weight loss per area correlates well with precorrosion alloy carbon content for the alloys that have similar chromium levels.

Figure 4. Schematic illustration of the final molten salt exposure capsule design for the static corrosion tests, which were successfully used in the present study (Anderson et al., 2010). 
Figure 5. Weight-loss per area for Incoloy-800H coupons exposed to molten FLiNaK salt showing (A) capsule type and exposure time at $850^{\circ} \mathrm{C}$; and (B) as a function of time at $850^{\circ} \mathrm{C}$ (Incoloy- $800 \mathrm{H}$ capsules only).

Figure 6. High temperature liquid salt loop for use with FLiNaK and $\mathrm{KCl}-\mathrm{MgCl} 2$ salts....................... 10

Figure 7. Heat transfer test section for high temperature salt loop...................................................... 11

Figure 8. Schematic of UW thermal flow meter design..................................................................... 12

Figure 9. Mixing element for thermal flow meter design. .................................................................... 12

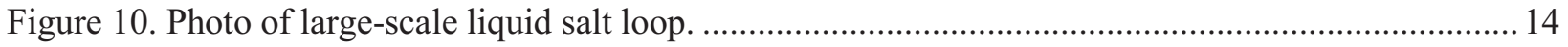

Figure 11. Photo of liquid salt valve and density level lance schematic................................................ 16

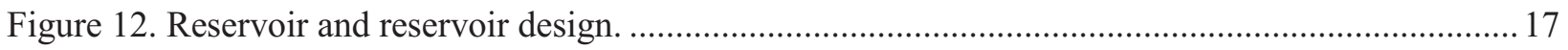

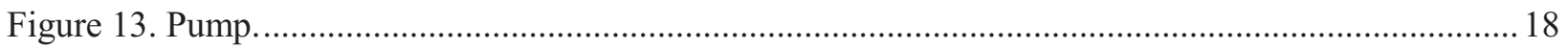

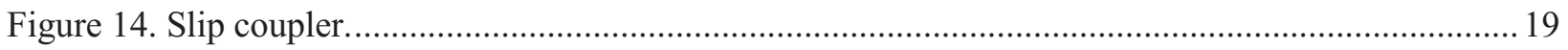

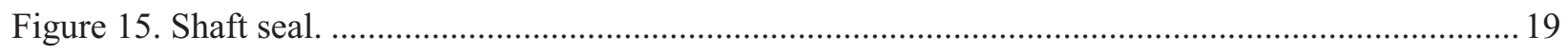

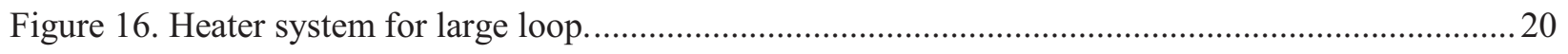

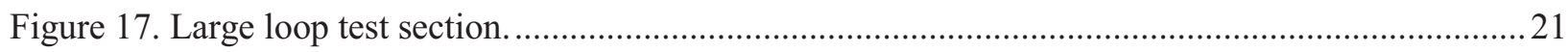

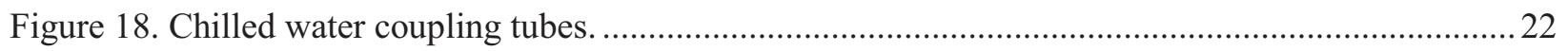

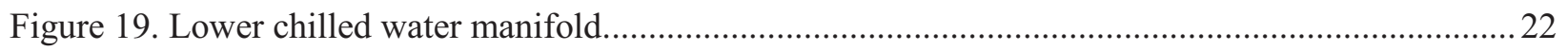

Figure 20. Schematic illustration of materials loop used for salt start-up and shut-down tests.................24

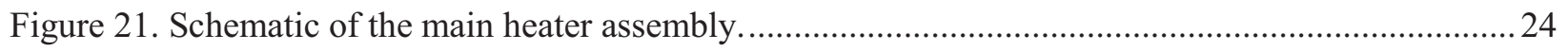

Figure 22. Liquid salt materials test loop used to perform the aqueous salt solution start-up...................25

Figure 23. Modified pump to prevent $\mathrm{KNO} 3$ and NaNO3 prills from entering the pump cavity before dissolution.

\section{TABLES}

Table 1. Comparison of corrosion rates of various alloys at $850^{\circ} \mathrm{C}$. 9 


\section{Molten Salts for High Temperature Reactor: University of Wisconsin Molten Salt Corrosion and Flow Loop Experiments - Issues Identified and Path Forward}

\section{INTRODUCTION}

The Department of Energy (DOE) is working with industry to develop a very high temperature reactor (VHTR) as a part of the effort to supply the United States with abundant, clean, and secure energy as initiated by the Energy Policy Act of 2005 (EPAct; Public Law 109-58, 2005). The Next Generation Nuclear Plant (NGNP) project, led by the Idaho National Laboratory (INL), will demonstrate the ability of the VHTR to generate hydrogen, electricity, and/or high-quality process heat for a wide range of industrial applications (INL, 2007). NGNP will be licensed by the U.S. Nuclear Regulatory Commission (NRC) and will meet or exceed current nuclear standards in reliability, nonproliferation, waste management, and security. Figure 1 presents a schematic of the proposed NGNP system.

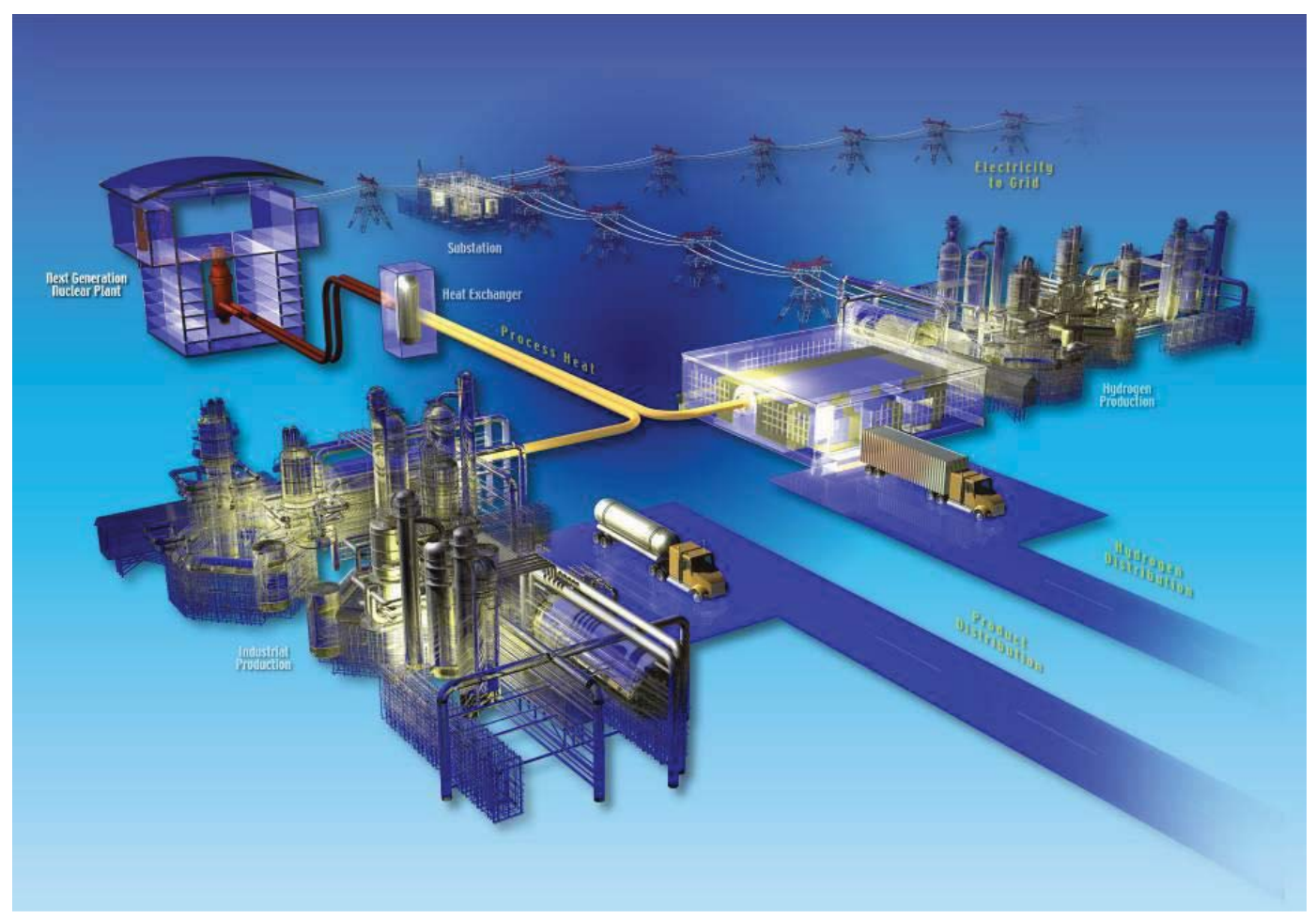

Figure 1. Schematic of the proposed NGNP system.

Molten salt technology has been used for many decades in industrial process heat transfer, thermal storage, and materials processing applications. The potential utility of molten salts as heat transfer agents was also demonstrated for nuclear reactors, as the liquid fuel in the Aircraft Reactor Experiment (ARE) and the Molten Salt Reactor Experiment (MSRE) programs. The behavior and material compatibility of various molten salts was studied extensively by Oak Ridge National Laboratory (ORNL) from the 1950s through the 1970s in support of the MSRE and the Molten Salt Breeder Reactor programs. Several types of molten salts, including $\mathrm{LiF}_{-} \mathrm{BeF}_{2}$ (also known as FLiBe [67-33 mol\%]), LiF-NaF-KF (also known as FLiNaK [46.5-11.5-42 mol\%]), and $\mathrm{KCl}-\mathrm{MgCl}_{2}$ (67-33 mol\%), have been investigated recently by several Japanese and U. S. groups ( $\mathrm{LiF}-\mathrm{BeF}_{2}$ and LiF-NaF-KF) and by the University of Wisconsin (LiF-NaF-KF and $\mathrm{KCl}-\mathrm{MgCl}_{2}$ ) in support of fusion reactor and $\mathrm{VHTR}$ reactor concepts, respectively. 
The NGNP is intended to increase energy efficiency in the production of electricity and/or provide high temperature heat for industrial processes. Four heat transfer molten fluids salts have been identified as possible candidates for use in the secondary side (for process heat application). For use of molten salt as a primary coolant fluid in the reactor system, candidate fluids must satisfy a number of requirements, including:

- Chemical stability at temperatures of $800^{\circ} \mathrm{C}$ or greater (for primary coolant)

- Radiolytic stability in a high radiation environment (for primary coolant)

- Low melting point and high boiling point

- Large specific heat and thermal conductivity

- Low vapor pressures, substantially less than one atmosphere at operating temperatures

- Compatibility with high-temperature alloys.

Molten salt as primary coolant offers several advantages owing to its thermo-physical properties, but at the same time, it introduces a set of technological and engineering challenges that are still being addressed. Fluoride salts (such as FLiBe and FLiNaK) have been considered as primary coolant, but chloride salts because of their high thermal neutron absorption cross section have never been considered as a fuel salt or primary coolant. (Chlorides could be used for primary coolants only if the salt is purified isotopically to ${ }^{37} \mathrm{Cl}$ to avoid nuclear transmutation issues.) However, because of the similarity of molecular structure and free energy of formation to fluoride salts, radiolytic and thermal stability is expected for the chlorides (Grimes, 1972). Molten chloride salts have long been applied by industry for heat transfer, heat treatments, high-temperature electrochemical coatings, and other processes. The corrosion characteristics have been studied for some common structural alloys in a variety of salts, but few data have been generated for eutectic $\mathrm{KCl}-\mathrm{MgCl}_{2}$. Limited data have been published for some highnickel alloys (Ambrosek, 2010; Olson, 2009; Sridharan, 2008).

In the present report, an overview of molten salts as a potential heat transfer coolant along with the experimental experiences at University of Wisconsin Molten Salt Program is presented. 


\section{MOLTEN SALTS AS POTENTIAL HEAT TRANSFER COOLANT}

The high temperature required for the process application (such as Hydrogen Production) and the required distance between facilities due to licensing restrictions restricts the number of heat transfer fluids that can be used to couple a nuclear plant with a process plant. In selecting a heat transfer fluid, it is desired to have a fluid that is stable at the maximum possible outlet temperature of the reactor. This restricts the heat transfer fluid to simple fluids, such as noble gases, simple alkali, and alkaline-earth halide salts. Of the noble gases, helium is one of the potential heat transfer fluids. Of the halide salts, fluoride salts and chloride salts are both stable options over the proposed operating temperature range for NGNP $\left(700-900^{\circ} \mathrm{C}\right)$. An additional consideration in choosing the one of these fluids is the pumping power required for the fluid.

Following are the characteristics that make the liquid salts potential candidates for process heat transfer applications (Sabharwall, et al. 2004):

- High Boiling Point

- Low Vapor Pressure

- Large Specific Heat and Thermal Conductivity

- High Density at Low Pressures.

The volumetric heat capacity is an important parameter in determining the amount of energy that can be contained in a unit volume of salt. The larger the volumetric heat capacity, the less salt is needed to transport the heat from the reactor to the chemical plant, which in turn provides the practical benefit of reduction in the size of the pumping equipment (Ambrosek, 2010).

The melting temperature of a salt mixture is the most important criteria in the selection of a salt. In the NGNP application, it is desired to get the melting temperature of the salt mixture to as low as possible, while still maintaining thermal stability of the salt at NGNP high operating temperatures. One way to lower the melting point of a salt is to combine multiple salts to form a salt of eutectic composition. These eutectic compositions have a much lower melting temperature than the individual salt components and are characterized by a single melting point. For example, for the FLiNaK salt, the individual constituents $\mathrm{LiF}, \mathrm{NaF}$, and $\mathrm{KF}$ have a melting point of 830,880 , and $912^{\circ} \mathrm{C}$, respectively. When the three components are combined to form a eutectic composition, FLiNaK, the melting point of the salt drops to $454^{\circ} \mathrm{C}$. These deep-well eutectic compositions are commonly formed in mixtures of salt components (Ambrosek, 2010). However, most ternary and higher order systems of salt mixtures do not have much experimental data available for the density, viscosity, thermal conductivity, etc.

The physical properties of molten salts in the liquid phase are similar to the properties of water at room temperature. Molten salts possess high volumetric heat capacities, $\rho$ CP. In addition, they have low vapor pressures $\left(<5 \mathrm{~Pa} @ 900^{\circ} \mathrm{C}\right)$, which in turn reduces the stress requirements in the piping. The thermal conductivity of molten salts is also quite high, in the range of approximately 0.4 to $1 \mathrm{~W} \mathrm{~cm}^{-1} \mathrm{~K}^{-1}$ bracketing the value of water at room temperature $0.6 \mathrm{~W} \mathrm{~cm}^{-1} \mathrm{~K}^{-1}$ (Ambrosek, 2010).

The use of salts as heat transfer fluid, instead of He, improves the efficiency of the whole reactor system, electric and hydrogen production, by up to $0.6 \%$ (Davis, 2005). This is if $50 \mathrm{MW}$ of the $600 \mathrm{MWth}$ is transported by use of FLiNaK salt to the hydrogen chemical plant. For comparison, it requires a $100^{\circ} \mathrm{C}$ temperature increase in the reactor outlet temperature to increase the efficiency of the whole plant, electrical and chemical, by 1.1\% (Ambrosek, 2010). This increase in efficiency from the use of salts increases NGNP's economic viability.

Much of the recent work in molten salt research has been performed by Anderson, Sridharan, and coworkers at the University of Wisconsin. Their research program has been multi-faceted and includes the following areas of work: 
- Static, isothermal screening of corrosion of a variety of alloys in FLiNaK and $\mathrm{KCl}-\mathrm{MgCl} 2$

- Construction of loop systems for evaluating heat transfer issues

- Thermal modeling

- Modeling of thermo-physical properties of salt compostions.

The research performed at the University of Wisconsin, along with the future directions identified as a result of this research, is summarized in the following sections. 


\section{UNIVERSITY OF WISCONSIN - MADISON MOLTEN SALT EXPERIMENTS AND LESSONS LEARNED}

The University of Wisconsin - Madison (UW) has done a considerable amount of work with fluoride salts $(\mathrm{FLiNaK})$, magnesium chloride salts $\left(\mathrm{MgCl}_{2}-\mathrm{KCl}\right)$, and nitrate salts $\left(\mathrm{NaNO}_{3}-\mathrm{KNO}_{3}\right.$ [40-60 wt\%], LiNO3-NaNO3-KNO3 [30-52-18 wt\%]). UW has conducted several studies over the past five years, including: (1) experiments to determine the best methods of small scale salt production and purification; (2) experiments to understand corrosion rates of different alloys and materials exposed to the salts for long durations (i.e., 100-1,000 hours) in a static system;

(3) experiments to study the exposure of the materials in flowing systems (1,500 hours);

(4) measurements and semi-empirical predictions of the thermal-physical properties of the salts;

(5) experiments to study the reaction rates with water and different hydrocarbons; and

(6) development of models to characterize the heat transfer characteristics and understand operational issues with respect to the use of the different salts. This section summarizes the lessons learned in each of these areas; details of the specific measurements and findings are presented in a series of additional reports prepared by the University of Wisconsin for DOE and industrial partners.

\subsection{Material Issues}

\subsubsection{General Corrosion Behavior and Trends}

Compatibility of molten salts with structural alloys centers on the potential for oxidation of the structural metal from the elemental state to the corresponding fluorides or chlorides with corresponding reduction of the oxidizing agent. Because molten salts are ionic and therefore electrical conductors, oxidation-reduction reactions will occur readily in this medium. Such oxidation-reduction (corrosion) can occur by several processes, including:

- Intrinsic corrosion (uniform surface corrosion) with molten salt as the reactant; this mechanism pertains primarily to nitrates and nitrites, not to fluorides or chlorides.

- Corrosion by oxidizing contaminants in the molten salts (such as $\mathrm{HF}, \mathrm{HCl}, \mathrm{H}_{2} \mathrm{O}$ ), residual oxides of metals, or easily reducible ions, especially some polyvalent metal ions. Impurities in the melt or in the gas phase control the corrosion/oxidation potential of the melt, increase the anodic reaction rate, or change the acidic or basic nature of the melt.

- Differential solubility due to thermal gradients (between hot and cold zones) in the molten salt system with formation of a metal ion concentration cell that drives corrosion.

- Galvanic corrosion, wherein alloys with differing electromotive potentials are maintained in electrical contact by the molten salt, driving the oxidation of the anodic material.

The laws of electrochemistry and mechanisms of corrosion are comparable for aqueous solutions and molten salts. The following corrosion mechanisms, which are commonly seen in aqueous environments, are also pertinent to molten salts (Lovering, 1983; Heine, 1982; Kane, 2003):

- Uniform surface corrosion

- Pitting corrosion

- Intergranular corrosion

- Galvanic corrosion.

In most corrosion and oxidation processes, alloys derive their resistance to corrosion from thin but dense, adherent protective oxide layers that passivate the surface. These generally are chromium, aluminum, or silicon oxide, which limit the diffusion of oxidants to the underlying alloy surface. Molten fluorides (and possibly chlorides) are excellent fluxes for oxides and will convert the metal oxide to the 
corresponding fluorides (or chlorides), which often are soluble in the molten salt (Kane, 2003;

Lovering, 1983). If the supply of oxidant is limited, as in the case of salt impurities in a sealed system, then the corrosion process will be limited and will cease once the oxidants are expended.

In general, there are three driving forces for corrosion in molten fluorides: impurities, temperature gradients, and activity gradients. The most common impurities in fluoride and chloride salts are oxides and hydroxides formed in the salt by its main constituents during contact with $\mathrm{H} 2 \mathrm{O}$ and $\mathrm{O} 2$ in air, as well as less prevalent metal impurities. $\mathrm{H} 2 \mathrm{O}$ and oxides are among the most deleterious contaminants in a molten fluoride salt from the standpoint of corrosion. The reaction of alkali fluorides with moisture generates gaseous HF that can then attack alloys.

The difference in the free energy of the salt constituents and the fluorides of the alloying elements is the key driving force for corrosion (Misra, 1987). Therefore, alkali metals (i.e., Li, Na, K) are the preferred cations for the salt constituents, and more noble materials (i.e., Ni) are appropriate for the structural container walls (Misra, 1987). Thus, alloys whose constituents have less negative free energies of fluoride formation are less prone to corrosion, and hence better candidates for heat transfer applications from a corrosion standpoint (Anderson et al., 2010).

Gibbs free energy of fluoride formation per F2 molecule of various metals present in the salt and materials at $1,027^{\circ} \mathrm{C}$ is shown in Figure 2. The more negative the Gibb's free energy of formation an alloy constituent is in comparison to the salt constituents, the more likely it is to dissolve in molten salt.

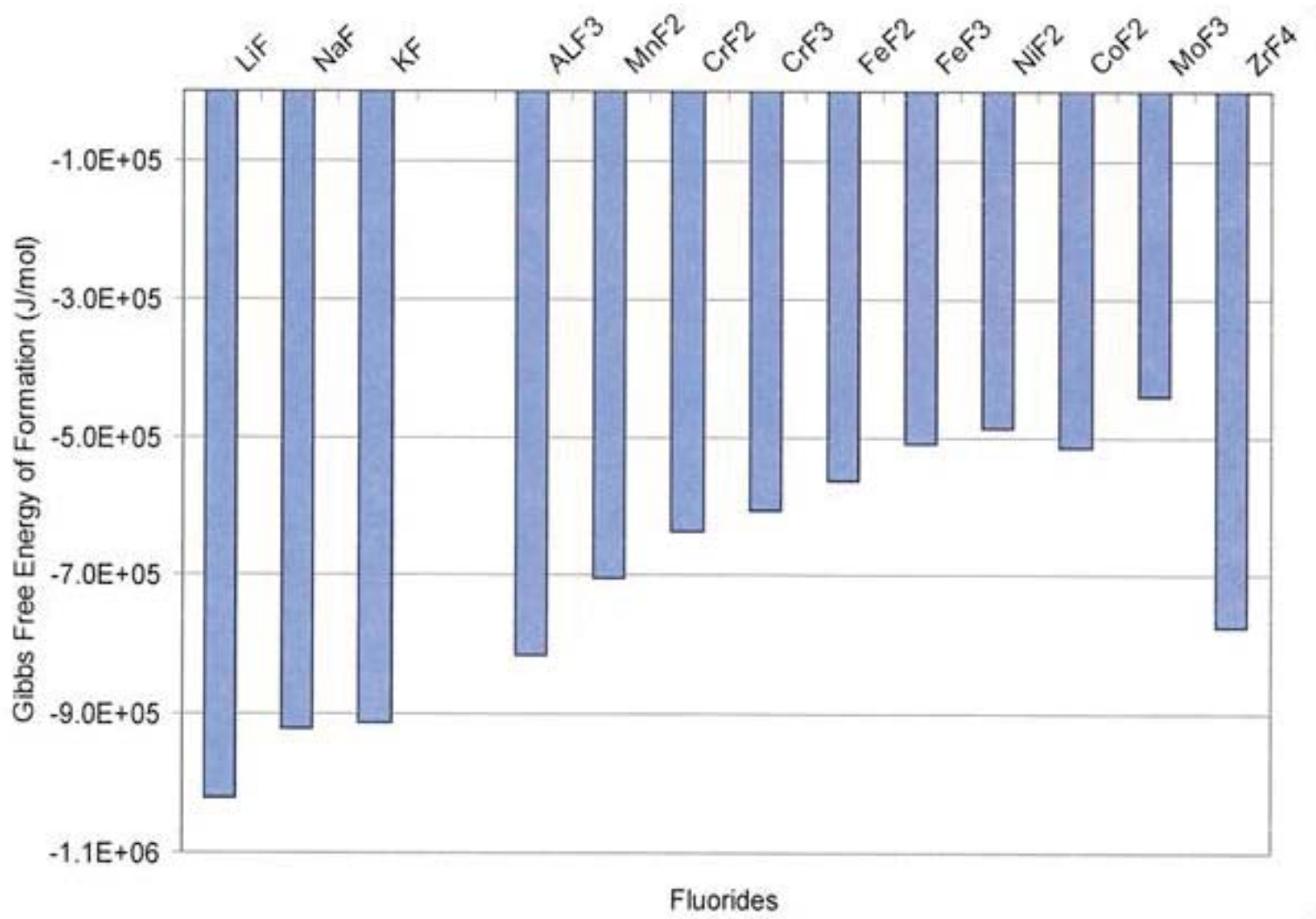

Figure 2. Gibbs free energy of fluoride formation per $\mathrm{F}_{2}$ molecule of various metals present in the salt and materials at $1,027^{\circ} \mathrm{C}$.

From corrosion tests performed in FLiNaK at the UW-Madison, it was found that the weight-loss per area of the exposed coupons correlated with the initial chromium content of the alloy as shown in Figure 3 (Olson 2009). 


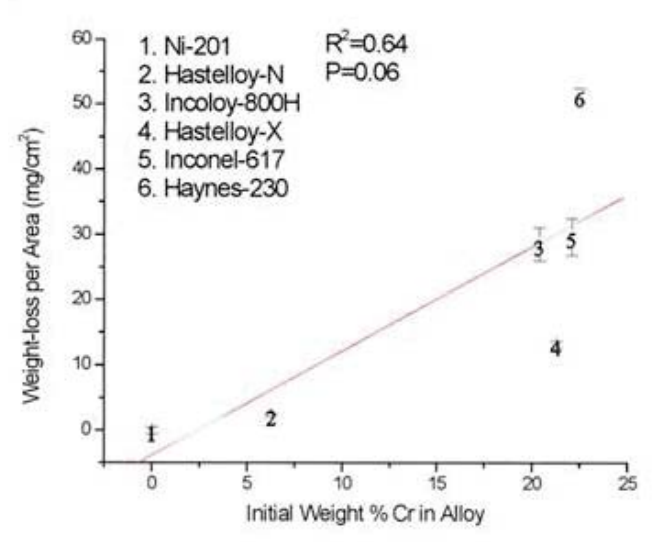

A

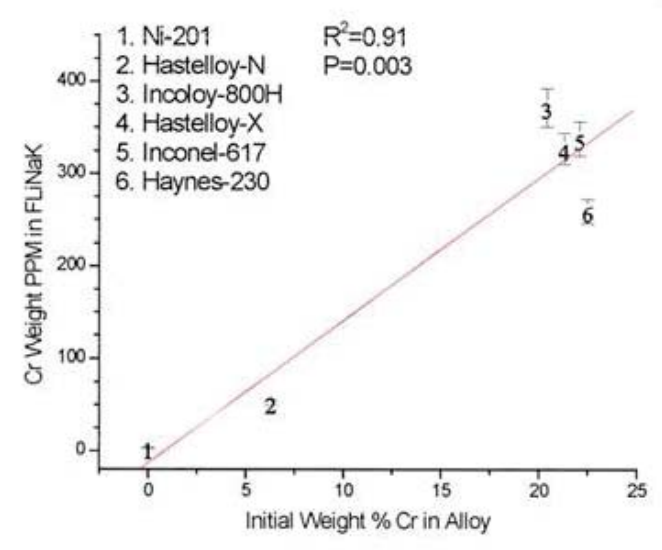

B

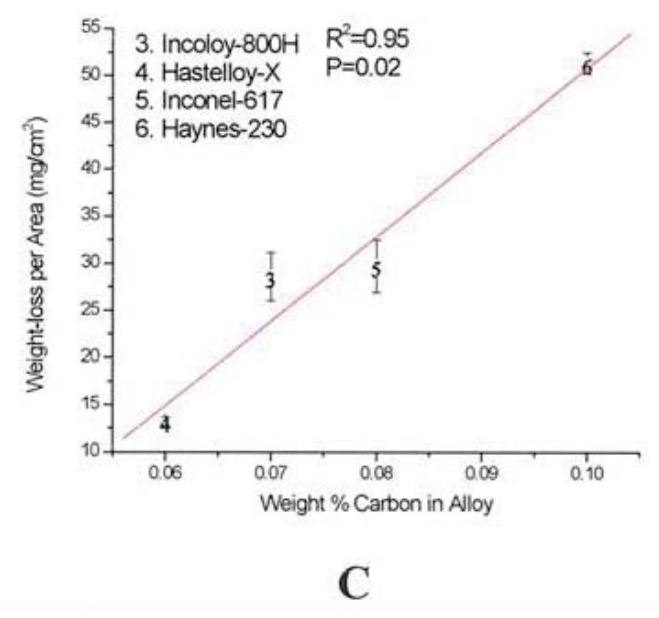

Figure 3. (A) The weight loss per area approximately correlates to the initial alloy chromium content. (B) Correlation between chromium in the salt after corrosion tests and the initial chromium content of the alloy. (C) Weight loss per area correlates well with precorrosion alloy carbon content for the alloys that have similar chromium levels.

\subsubsection{Container Material Influence on Corrosion}

Molten salts are ionic fluids that can sustain electrical currents and electrochemical corrosion mechanisms that depend on electron transfer. The design considerations for molten salt coolant systems usually dictate the use of several different materials, which may have differing electromotive potentials (galvanic potentials). Unfortunately, galvanic potential rankings have not been developed for molten salts. The corrosion rate of a chromium-containing alloy can be accelerated considerably by a galvanic couple; corrosion rates can be increased more than 30 times by switching from an inert crucible to one comprised of a more reactive metal, such as iron (Ozeryanaya, 1985). The process has been observed in corrosion of Incoloy $800 \mathrm{H}$ in $\mathrm{FLiNaK}$, in which the corrosion rate was significantly greater for a graphite crucible compared to an Incoloy 800H crucible (Olson, 2009; Sridharan, 2009).

A graphite test cell was built at UW for initial alloy screening with FLiNaK salt, and different FLiNaK purification methods, to compare FLiNaK against $\mathrm{KCl}-\mathrm{MgCl}_{2}$ and to test several coatings. The final molten salt exposure capsule design is shown in Figure 4. 


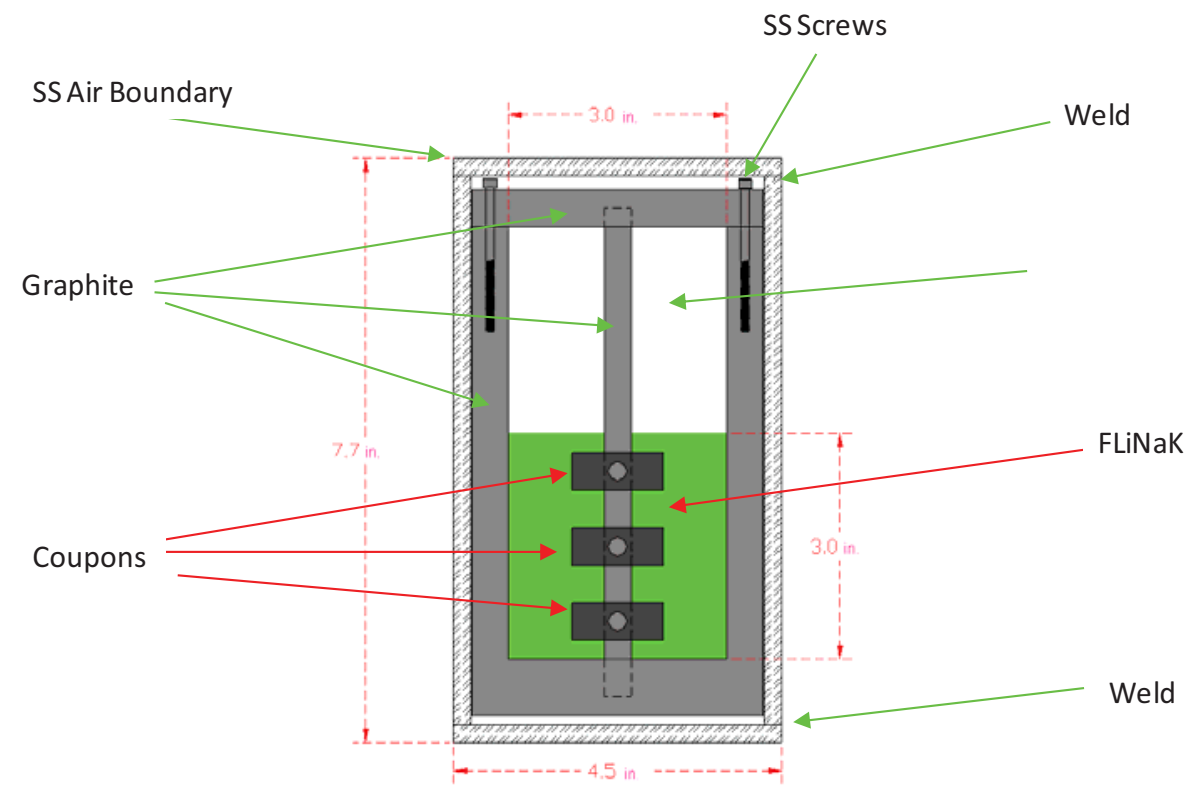

Figure 4. Schematic illustration of the final molten salt exposure capsule design for the static corrosion tests, which were successfully used in the present study (Anderson et al., 2010).

After initial alloy screenings utilizing graphite capsules, an Incoloy- $800 \mathrm{H}$ capsule was used to investigate Incoloy- $800 \mathrm{H}$ corrosion without the acceleration from graphite. The weight loss measured from the Incoloy- $800 \mathrm{H}$ coupons in the Incoloy-800H capsules were two orders of magnitude less in comparison to the tests in the graphite capsules (see Figure 5). This difference in weight loss highlights the increase in corrosion of the alloy coupons due to graphite. It was found that the graphite crucible further accelerated the chromium dissolution process by way of forming chromium-carbide phases for the chromium-containing alloys.

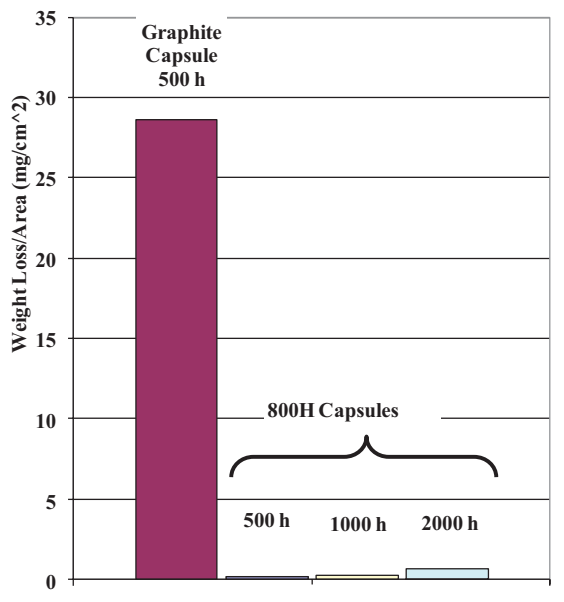

A

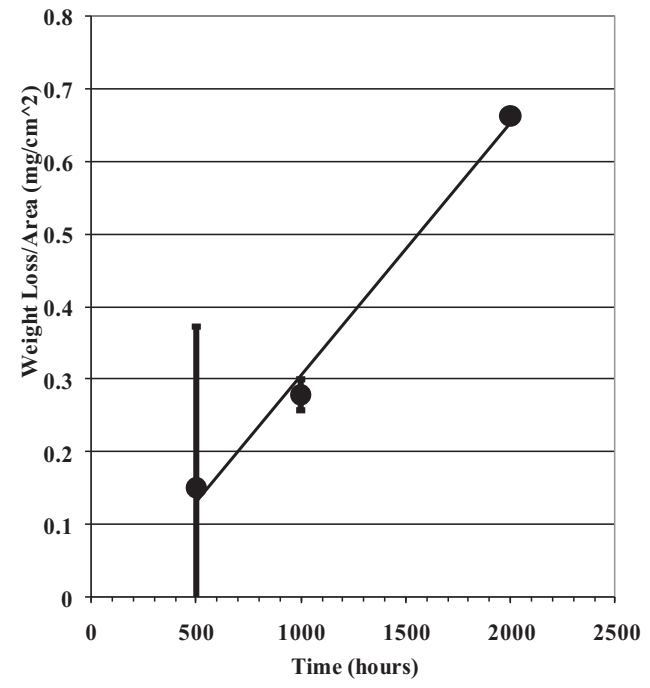

B

Figure 5. Weight-loss per area for Incoloy-800H coupons exposed to molten FLiNaK salt showing (A) capsule type and exposure time at $850^{\circ} \mathrm{C}$; and (B) as a function of time at $850^{\circ} \mathrm{C}$ (Incoloy- $800 \mathrm{H}$ capsules only). 
It is believed that an acceleration of chromium dissolution in FLiNaK from high chromium alloys in graphite containers occurred due to interactions of $\mathrm{Cr}^{2+/ 3+}$ with the alloy, salt, and graphite. Chromium dealloys from the samples and forms chromium fluorides in the salt; the chromium in the salt then deposits on the graphite from solution. This process continues until a thermodynamic equilibrium is established between the alloy, salt, and crucible.

\subsubsection{Material Rankings as Measure of Corrosion (with FLiNaK)}

The tests by Olson, et al (2009) and Sridharan, et al (2009) generated corrosion rates for various alloys, in which the corrosion was driven by a chromium/iron dissolution and deposition mechanism (probably galvanic corrosion), as well as contaminant corrosion rates for Incoloy $800 \mathrm{H}$ in FLiNaK. On the basis of sample mass loss as a measure of corrosion, the high-nickel alloys rank as follows:

- Haynes $230>$ Inconel $617>$ Incoloy 800H > Hastelloy X > Hastelloy N > Ni-210.

On the basis of dissolved chromium content as a measure of corrosion, the alloys rank as follows:

- Incoloy $800 \mathrm{H}>$ Haynes $230>$ Hastelloy $\mathrm{X}>$ Hastelloy $\mathrm{N}>\mathrm{Ni}-210$.

On the basis of grain boundary attack as a measure of alloy degradation, the alloys rank as follows:

- Haynes $230>$ Incoloy 800H > Hastelloy X > Inconel $617>$ Hastelloy N > Ni-210.

\subsubsection{Measure of Corrosion (with $\mathrm{KCl}-\mathrm{MgCl}_{2}$ )}

Of the various alloys, Haynes 230 exhibited the least mass loss from the exposure to molten $\mathrm{KCl}$ $\mathrm{MgCl}_{2}$, while Hastelloy $\mathrm{N}$ exhibited the least grain boundary attack and chromium dissolution. Despite moderate mass loss, 316 stainless steel (SS) exhibited the worst grain boundary attack with chromium depletion to 300 microns depth during the 100 hour exposure.

Corrosion rate data generated by Olson, et al (2009) and Sridharan, et al (2009) for the various alloys in FLiNaK and in $\mathrm{KCl}-\mathrm{MgCl}_{2}$ are shown in Table 1. The data shows substantial differences in corrosion rates between the two salts, but the differences may reflect the effects of galvanic corrosion for those tests with graphite crucibles and oxidation for those tests with $\mathrm{SiO}_{2}$ crucibles.

Table 1. Comparison of corrosion rates of various alloys at $850^{\circ} \mathrm{C}$.

\begin{tabular}{|l|l|c|l|c|}
\hline \multicolumn{1}{|c|}{ Alloy } & \multicolumn{1}{|c|}{$\begin{array}{c}\text { FLiNaK } \\
\text { Crucible }\end{array}$} & $\begin{array}{c}\text { Corrosion Rate } \\
(\mathrm{mm} / \mathrm{y})\end{array}$ & $\begin{array}{c}\text { KCl-MgCl } \\
\text { Crucible }\end{array}$ & $\begin{array}{c}\text { Corrosion Rate } \\
(\mathrm{mm} / \mathrm{y})\end{array}$ \\
\hline Hastelloy N & graphite & 0.045 & quartz & 1.1 \\
\hline Hastelloy X & graphite & 0.28 & quartz & 1.1 \\
\hline Inconel 617 & graphite & 0.62 & quartz & 1.3 \\
\hline Haynes 230 & graphite & 1.0 & quartz & 0.67 \\
\hline Incoloy $800 \mathrm{H}$ & graphite & 0.63 & quartz & 1.4 \\
\hline Incoloy $800 \mathrm{H}$ & Incoloy $800 \mathrm{H}$ & 0.0033 & graphite & 0.24 \\
\hline
\end{tabular}

\subsubsection{Coatings for Surface Passivation}

Several coatings and post-processing techniques were investigated at UW. For iron- and nickel-based alloys, nickel electroplating, molybdenum thermal spray, and diamond like coatings were studied. The Ni-electroplating was the most promising of the coatings studied for alloys; the Mo thermal spray and diamond like carbon coatings had spalling issues. The Ni-plating was shown to greatly reduce the rate of corrosion due to chromium dealloying from the base alloy (Anderson et al., 2010). 
A ceramic with the $\mathrm{SiC}$ and pyrolytic carbon coating also showed virtually no signs of corrosion compared to an uncoated sample. In the uncoated $\mathrm{C} / \mathrm{SiSiC}$ composites, the pure Si regions were selectively attacked in both FLiNaK and $\mathrm{KCl}-\mathrm{MgCl} 2$.

\subsection{Heat Transfer Issues}

\subsubsection{Description of the Loop}

A high-temperature molten salt flow loop and its main components are pictured and labeled in Figure 6. The direction of the flow is clockwise from the reservoir tanks, to the pump, through the thermal flow meter, followed by the heat transfer test section, and finally returning to the reservoir tanks. The flow loop is constructed with $316 \mathrm{SS}$ tubing (1-in. OD, 0.12-in. wall), uses type $\mathrm{K}$ thermocouples, and is insulated with Kaowool and Pyrogel XT. The main components of the molten salt loop are the reservoir tanks, a centrifugal impeller high temperature liquid salt pump, a high temperature thermal mass flow meter, an up-flow heat transfer test section, and a laser-based manometer. Each of the components had to be carefully designed with respect to the operating conditions that it would see during loop operation. The minimum requirement was that the different components needed to operate above the melting point of the liquid salts of interest $\left(454^{\circ} \mathrm{C}\right.$ for $\mathrm{FLiNaK}$ and $426^{\circ} \mathrm{C}$ for $\left.\mathrm{KCl}-\mathrm{MgCl}_{2}\right)$. To provide a significant margin, the base design was selected to ensure that all of the components could operate at temperatures of $600^{\circ} \mathrm{C}$ or greater. The maximum flow rate in the loop is limited by the available power input and removal, approximately $4 \mathrm{~kW}$.

There are currently two heat transfer test sections, a $1 / 2$-in. OD (0.37-in. ID) and a $1 / 4-i n$. OD (0.085-in. ID), which have been used in the loop. Figure 7 is a schematic of the test sections. Both test sections are single-channel cylindrical tubes that have abrupt constrictions and expansions from the 1 -in. tube to the $1 / 2$ or $1 / 4$-in. tube. The smaller diameter portion of each test section is wrapped with a NiCr 60 heating wire (red section of schematic) and has five thermocouples welded to the wall (TSH1 through 5), equally spaced every six in. over the total 24 in. length. The inlet (TSHIN) and outlet (TSHOUT) center-line temperatures for the test sections are measured with $1 / 4$-in. diameter thermocouples.

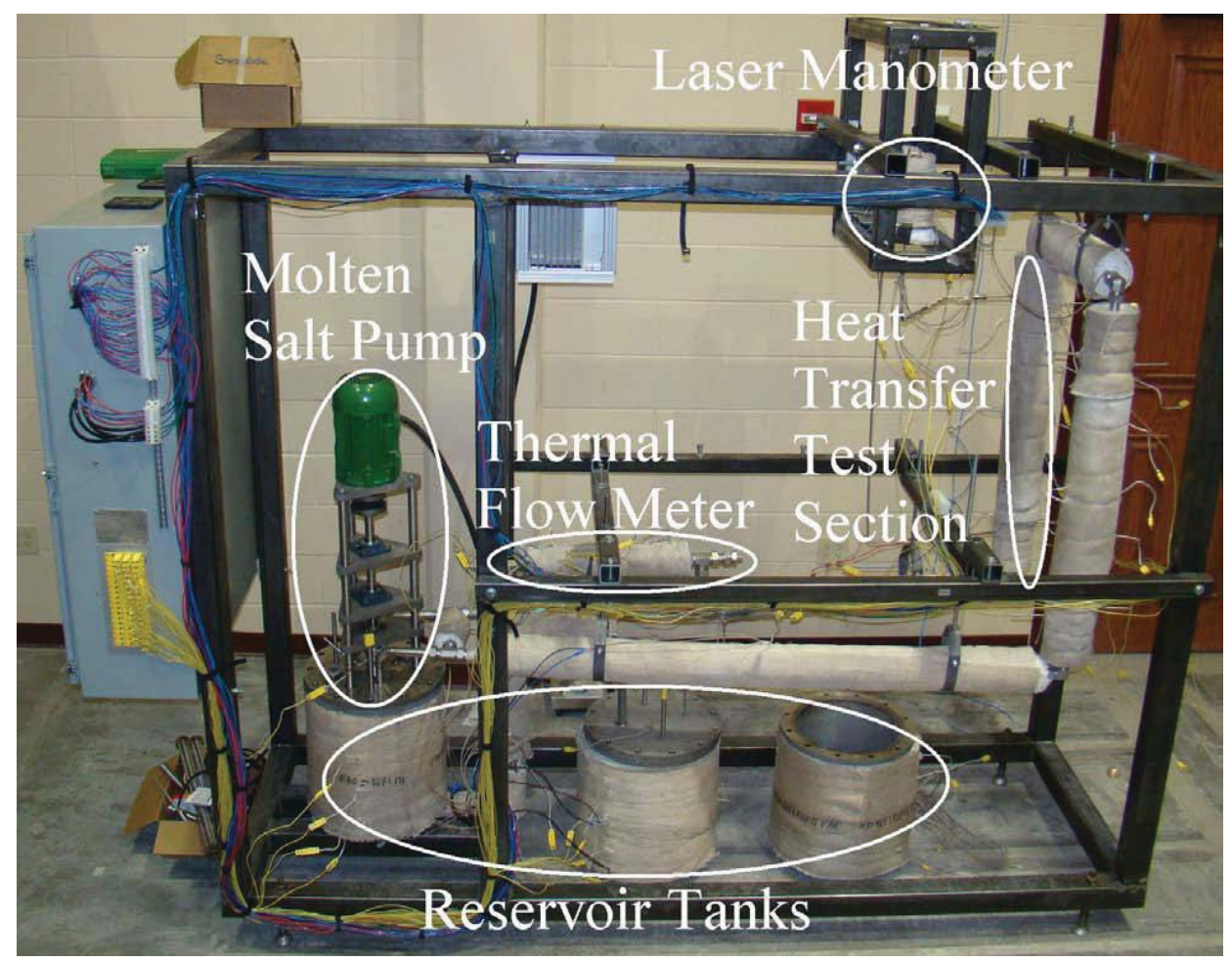

Figure 6. High temperature liquid salt loop for use with $\mathrm{FLiNaK}$ and $\mathrm{KCl}-\mathrm{MgCl} 2$ salts. 


\subsubsection{Operational Issues}

The melting point of the $\mathrm{MgCl} 2-\mathrm{KCl}$ eutectic mixture is $426^{\circ} \mathrm{C}$ and $\mathrm{FLiNaK}$ is $454^{\circ} \mathrm{C}$. To prevent freezing during operation, it was decided that the handling in the liquid state would be conducted at a minimum temperature of $500^{\circ} \mathrm{C}$. This is above the operating temperature for most conventional pressure gauges, flow meters, and pumps. In addition to the temperature limitations, the fact that the loops operated at relatively low flow rates, and correspondingly low pressure drops, limits the number of commercial instrumentation options that were available and/or increases the cost of such instrumentation. Therefore, it was decided that in-house (at UW) devices would be used to reduce costs and obtain the desired level of accuracy under these conditions. Below is a summary of some of the components.

\section{Pressure Drop Measurement}

There are commercially available pressure sensors that can operate above $500^{\circ} \mathrm{C}$, such as the sodiumpotassium $(\mathrm{NaK})$ filled pressure transmitters from ONEHalf2 $0^{\mathrm{a}}$ or Gefran ${ }^{\mathrm{b}}$, which are rated for up to $1,000^{\circ} \mathrm{F}\left(538^{\circ} \mathrm{C}\right)$. Of these NaK-filled pressure sensors, the gauges with the smallest pressure ranges are on the order of 0 to $500 \mathrm{psig}$ ( 0 to $35 \mathrm{bar}$ ) with a full scale error of $+/-0.5 \%$, or $2.5 \mathrm{psi}(0.17 \mathrm{bar})$. Under laminar flow conditions in the 0.37 -in. and 0.085 -in. ID test sections, a maximum pressure drop (in the 0.085 -in. ID test section at a Reynolds number of 2,300) of approximately 3.2 psi ( 0.22 bar) is expected. This level of error was deemed unacceptable, and an in-house solution to measure low pressure differences was developed. It should be noted that Rosemount could provide NaK filled low DP pressure gauges if several (10's) of gauges were needed. The cost and setup was too high for a single pressure gauge. Also, the capillary tubes can be filled with $\mathrm{NaK}$ in house (at UW) if necessary.

To measure the differential pressure across a test section, taps at the bottom and top of a test section are connected to sealed "pressure cans." When working with reactive liquids, the head space in the pressure cans is to be filled with an inert gas. Above each pressure can, a laser level indicator is directed through a quartz window, and reflects off the liquid's surface. Each laser has its own detector, and the distance from the laser to the reflective surface can be determined based on the location that the reflected beam contacts the detector. In transparent liquids, a stainless or nickel boat floats on the surface to increase the intensity of the reflected beam. By measuring the distance to the reflective surface, or the height of the liquid in each pressure can, and knowing the density of the liquid, the differential pressure can be determined. This device achieved an accuracy of \pm 0.003 in $\mathrm{H}_{2} \mathrm{O}\left(0.9 \mathrm{~Pa}\right.$ or 0.000009 bar at $\left.4^{\circ} \mathrm{C}\right)$ during preliminary tests.

\section{Flow Meters}

There are commercially available flow meters that can operate at high temperatures, but require flow rates that are significantly greater than those used in the laminar flow loop. GE produces ultrasonic flow meters, or bundle waveguide transducers (BWT), that can operate at temperatures of up to $600^{\circ} \mathrm{C}$. The smallest diameter BWT that GE produces has a 2-in. ID and requires a minimum velocity of $0.03 \mathrm{~m} / \mathrm{s}$ for a liquid. Under these conditions, the minimum flow rate for $\mathrm{KCl}-\mathrm{MgCl}_{2}$ would be greater than $5,000 \mathrm{~g} / \mathrm{min}$, while the experiments are to be run at flow rates on the order of $50 \mathrm{~g} / \mathrm{min}$. Foxboro model $83 \mathrm{~F}-\mathrm{T} 01$ series vortex flow meters capable of temperatures up to $430^{\circ} \mathrm{C}$ in liquid salts are also commercially available; however, these are limited to Reynolds numbers above 5000 and are too close to the melting temperature of the $\mathrm{KCL}-\mathrm{MgCl}_{2}$. Since no commercially-available flow meters were found that operate at low flow rates and sufficiently high temperatures, a custom thermal

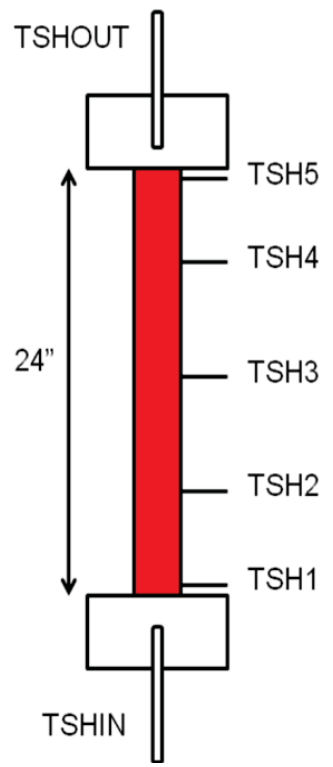

Figure 7. Heat transfer test section for high temperature salt loop.

a. 193 Roe Avenue, Toronto, Ontario, Canada, M5M2J1; Telephone: (416) 781-1881.

b. 8 Lowell Avenus, Winchester, MA, 01890; Telephone: (781) 729-5249. 
flow meter (TFM) was designed. The GE flow meters are being tested in a nitrate salt loop along the vortex flow meters, which have a maximum limit of $430^{\circ} \mathrm{C}$. Currently, the ultrasonic flow meters are not producing accurate results and it is thought that this is due to the power of the transmitter. UW is working with GE to determine possible solutions to this problem. It does not seem to be an issue with the salt, however, but rather with the small 2-in. tube geometry and the strength of the ultrasonic beam that is being used.

A traditional TFM uses the energy balance, $\mathrm{Q}=\mathrm{mC} \Delta \mathrm{T}$ to directly solve for $\mathrm{m}$. Using the energy balance, the mass flow rate, $\mathrm{m}$, can be determined since the power input, $\mathrm{Q}$, is controlled, the inlet and outlet temperatures can be measured, and the average heat capacity of the fluid can be determined based on the temperature measurements. A simple schematic of the flow meter that was designed at UW-Madison is shown in Figure 8.

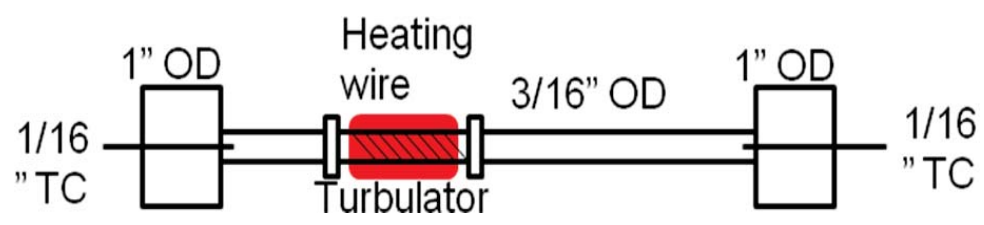

Figure 8. Schematic of UW thermal flow meter design.

In this TFM, a NiCr 60 resistance wire is used for heating. To enhance heat transfer and mixing, the heating wire was wrapped around a 6-in. long Koflo stratos tube mixer, as shown in Figure 9.

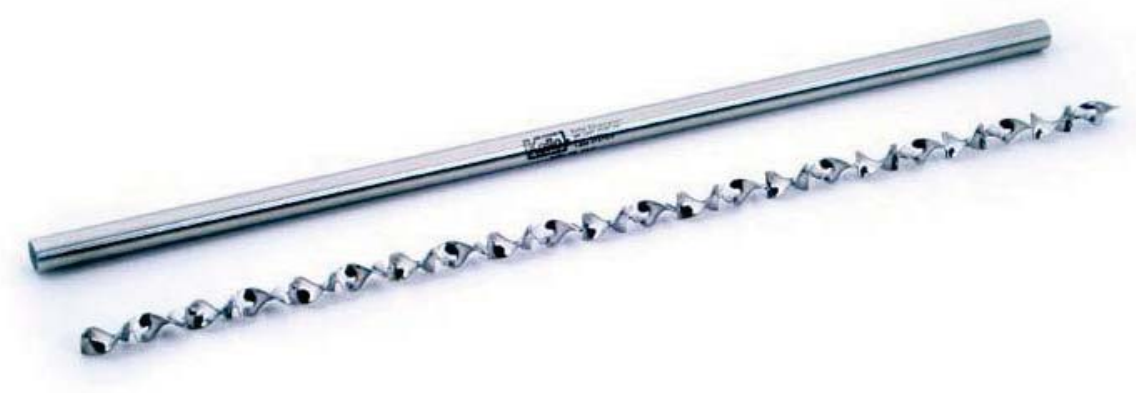

Figure 9. Mixing element for thermal flow meter design.

The inlet and outlet centerline temperatures were measured by $1 / 16$-in. thermocouples and were assumed to be equal to the bulk temperature of the fluid. The TFM has been tested with Paratherm NF, a heat transfer oil, and all flow rate measurements taken fell within $\pm 10 \%$ of the flow rate measured by a coriolis flow meter once convective and resistive heat losses were taken into account. Recent tests have determined the accuracy to be $+/-5 \%$ for the conditions being tested. This is above the accuracy of the literature values for the specific heat of the $\mathrm{KCl}-\mathrm{MgCl}_{2}$.

\section{Pumps}

A fairly large search of different pump manufacturers was performed, but no conventional stock pumps were found that could operate at sufficiently high temperatures under the flow rates that were desired for the UW test loops. Custom-built pumps were available from some companies; however, the quoted prices were deemed prohibitively high and the specifications were not sufficient to warrant purchase. Larger scale pumps could be procured from several companies, including Lawrence pumps, Nagel pumps, and Friatec.

A conventional 316 SS centrifugal pump was modified in-house to allow it to operate at temperatures up to $600^{\circ} \mathrm{C}$. 


\section{Seals}

Several different sealing technologies have been studied and the appropriate choice depends on the temperature and the environment. Teflon or graphite packing can be used for rotating seals, such as the pump lower seal assembly. However, Teflon has a maximum temperature rating of approximately $300^{\circ} \mathrm{C}$ and graphite has a maximum temperature limit of about $500^{\circ} \mathrm{C}$ in an oxidizing environment. The seal can be actively cooled to hold below these temperature limits and seems to work well. UW used graphite for the main pump system with an inert gas flush along with active cooling to maintain it to temperatures below $500^{\circ} \mathrm{C}$. Flat graphite, Teflon, and vermiculite seals have also been used (asbestos seals had been used in past solar salt systems with good results, but were not tested at UW due to health hazard issues). It was found that spiral wound seals hold up better for long term operations $>1,000$ hours.

\section{Joining}

The best method for joining pipe sections is welding. UW has used compression fittings, VCR fittings, Grayloc, and flange fittings. The VCR fittings work well for smaller connections $(\sim 1 / 4$-in. tubing), compression fittings have also been used for diameters of up to 1.25-in. and have worked fairly well provided they are tightened to specifications (hydraulically swaged for larger than 1-in. tube) and cleaned thoroughly between attempting resealing. They are more difficult to remove, however, due to the wetting of the compression seal surface. To connect larger pipes and to seal off reservoir cans, flange fittings with an appropriate seal can be used (typically a spiral wound graphite or vermiculite). Grayloc fittings with stainless seal rings have been found to work best for pipe connections and allow quick and fairly easy removal.

\section{Valves}

There are commercial valves that will work with the salt. Typically, these rely on long stems and graphite packing for the seals. For small valves, bellows type valves are useful to limit contact with oxidizing environments. Vogt or Swageloc offer valves that work well under these conditions and are able to go temperatures of $800^{\circ} \mathrm{C}$, if necessary.

\subsubsection{Nitrate Salt Large Heat Transfer Loop}

As pictured in Figure 10, the liquid salt flows through the loop counter-clockwise. The liquid is pumped via a $7.5 \mathrm{hp}$ Nagle cantilevered pedestal pump modified for $15 \mathrm{psi}$ reservoir pressures. The pressurized salt flows out the discharge of the pump through the exit in the bottom of the pump reservoir and into the heater section. In this section, the salt may receive heat from the three internal multicell heaters and/or from six external tape heaters. The salt then flows vertically downward through the transfer tube, through the throttling valve at an angle of 2 degrees below horizontal, and then vertically upward through the test section. At the top of the test section, the flow turns to an angle of 20 degrees over horizontal, flows through the Panametrics ultrasonic flow meter, and then returns to the pump through the diffuser. When not in use, the salt is stored in the reservoir at the lower left. It is planned that all melting and freezing will occur in this reservoir. Transfer between the reservoir and loop is accomplished by pressurizing the appropriate overhead gas and opening the transfer valve between the reservoir and loop.

\section{Piping and Elbows}

The loop piping consists of 2-in. NPS, Schedule 40, seamless, 316/L SS. Straight 316 SS was desired for the high temperature application, but was not commercially available. The tubes were initially prepared for welding/assembly, and then chemically cleaned. The corners of the loop are 2-in. NPS, long radius, Schedule 40,316/L SS, 90-degree elbows. All elbows were custom-machined to match the nonstandard corner angles (necessary for draining). All welds on the loop are multipass TIG with the appropriate ASME Pressure Vessel Code procedures followed. No adverse issues have been encountered with the welds or piping. 

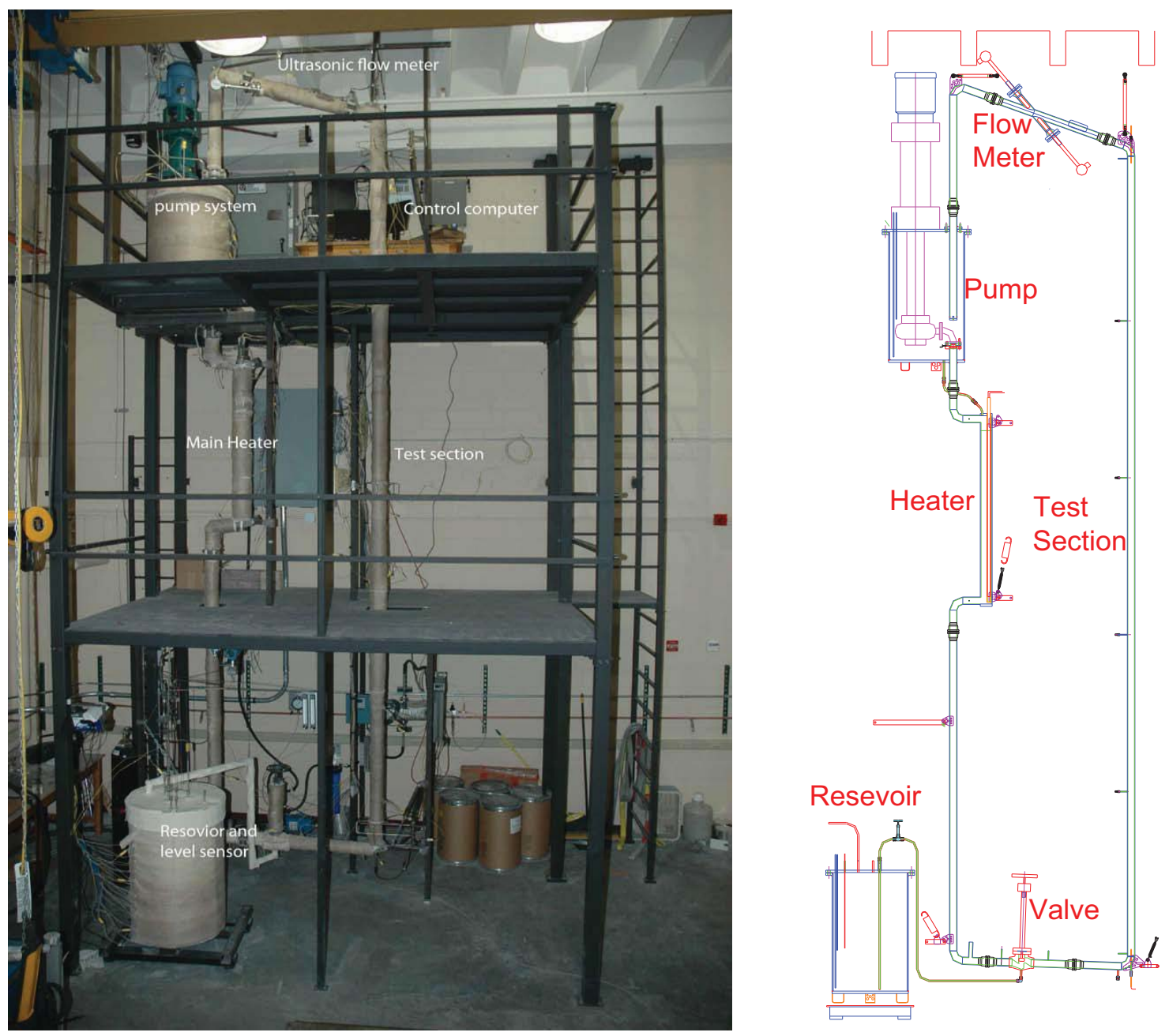

Figure 10. Photo of large-scale liquid salt loop.

\section{2-In. Pipe Fittings}

All breakable 2-in. joints in this loop are constructed with Grayloc fittings. A literature search revealed these types of closures to be the most robust for high temperature liquids, particularly when rapid temperature transients are involved. These types of closures have the added benefit of small physical size, which eases assembly, insulation, and helps to minimize pre-heat time. The Grayloc hubs are 316 SS, Schedule 40, 2-in. butt weld. The seal rings are 316 SS sized to match the hubs and silverplated. The clamps and bolting are also 316 SS. All Grayloc parts were standard, except the silver plating on the seal rings. No adverse issues have been encountered with the Graylocs to date. There is not yet adequate data to estimate the number of times the joint may be broken and still maintain the seal integrity.

\section{Tubing and Fittings}

All salt wetted tubing used on the loop is 316 SS seamless. All fittings for this tubing are Swagelok, 316 SS, compression type. The Swagelok fittings have been a robust closure in this work, but have a drawback. To disassemble a salt wetted compression type fitting, it has been found necessary to heat the fitting, sometimes well above the melting point of the salt. It has also been found that the life of the fitting is four to five disassembly cycles. This varies greatly with the service temperature. The 316 tubing has proven very durable with one exception. In previous work on the materials loop, a 1/4-in. tube ruptured when salt was frozen and re-melted in the tube. This was attributed to a non-ideal directional heating 
scenario. VCR type fittings were also used and elevated some of the issues with breaking the connection, but the cost and time for installation is higher.

\section{Trace Heat}

All trace heat on the loop utilizes HTS/Amptek, high watt density, heavy insulated heating tapes. A search of available trace heaters determined these to be the highest powered option. These tapes have a stated maximum temperature of $760^{\circ} \mathrm{C}$ with a manufacturer estimated difference of $85^{\circ} \mathrm{C}$ between the tapes and platen at maximum power. The tapes were installed directly onto the stainless piping in a spiral fashion, with insulation placed directly over the tape. All trace heat circuits were switched with solid-state relays of the appropriate capacity. These relays were, in turn, controlled via the LabView Data Acquisition system. Temperatures to control trace heat were received from K-type thermocouples and welded directly to stainless material being heated.

The 2-in. piping was heated at approximately $200 \mathrm{~W} / \mathrm{ft}$, and this has proven adequate. This trace heating method has had two main drawbacks: once heated, the tapes are very sensitive to abrasion and movement in general, and the insulation on the tape is a very proficient wick for the salt, and once wetted, the heater soon fails. Other than these two issues, the tapes have proven reliable. Bare nichrome wire was also used for smaller tubes and worked well; which consisted of a wrap of high temperature ceramic tape (Scotch 69).

\section{Insulation}

As previously stated, insulation on the loop was installed directly over the trace heaters. The insulation, in general, consists of a base, single $1 / 4$-in. thick layer of Kaowool S $\left(8 \mathrm{lb} / \mathrm{ft}^{3}\right)$ thermal blanket wrapped directly over the trace-heated tube. Two layers of 0.2-in. thick Pyrogel XT were wrapped over the base layer of Kaowool. One layer of high temperature silica fabric (density of $40 \mathrm{oz} / \mathrm{sq} \mathrm{yd}$ ) was wrapped over the Pyrogel. All seams were staggered to minimize heat loss. The single layer of Kaowool thermal blanket was installed to maintain the Pyrogel XT below its maximum service temperature of $650^{\circ} \mathrm{C}$. The single layer of silica fabric was utilized to contain the copious amounts of dust generated by the Pyrogel XT. No adverse issues have been encountered with this insulation method to date, although all layers can be wetted by the salt.

\section{Valves}

Two valves were utilized in this loop. In the lower section of the main loop, a 2-in. NPS globe valve was installed to facilitate throttling, if necessary. The valve chosen was a Vogt class 800 globe valve with conventional port and socket weld ends. This valve is made for cryogenic service with socket weld ends and is forged of $316 \mathrm{SS}$. It is manufactured to utilize a spiral wound bonnet gasket and includes a bonnet extension of approximately 18 -in. in length. When received, this valve was refitted with a 316 SS spiral wound Thermiculite 835 bonnet gasket from Flexitallic. At this time, the stem packing was also replaced with glass-filled Teflon washers from a local vendor. To maintain the temperature of the Teflon stem packing below its upper service limit, the bonnet extension is wrapped with a dedicated trace heater, controlled by a dedicated circuit, which maintains the packing end of the bonnet at approximately $200^{\circ} \mathrm{C}$. No adverse issues have been encountered with this valve.

A Swagelok $1 / 2$-in. tube size SS-8BW-TW was installed in the transfer line between the reservoir and loop. This valve is manufactured with one-half Swagelok compression fittings integral to the valve and has an upper service limit of $482^{\circ} \mathrm{C}$. This valve is trace-heated with one dedicated circuit. No adverse issues have been encountered with this valve, which is shown in Figure 11. 

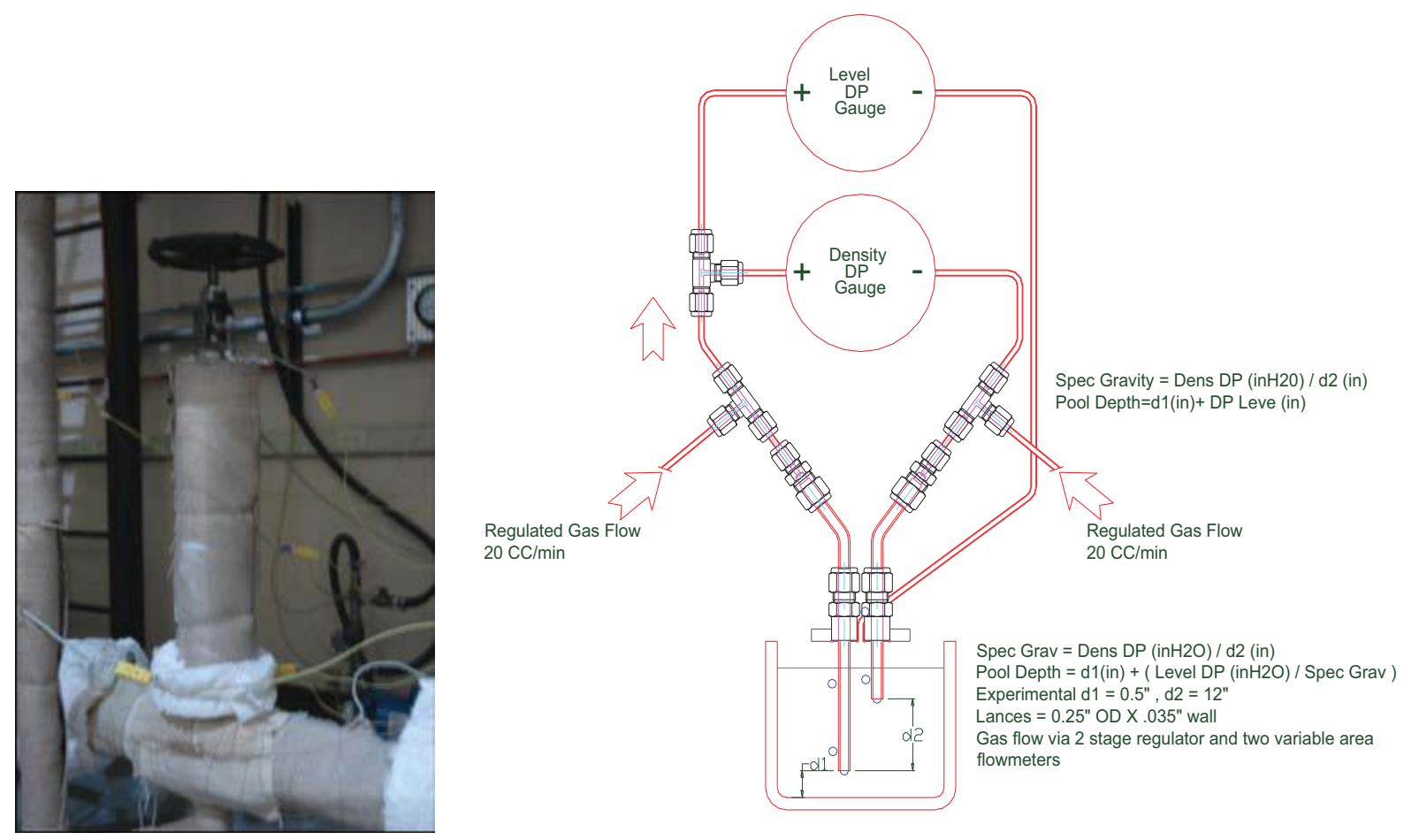

Figure 11. Photo of liquid salt valve and density level lance schematic.

\section{Reservoir}

To safely freeze and melt the salt for this experiment, a large reservoir was fabricated onsite, as shown in Figure 12. The reservoir base consists of a water jet cut 3/4-in. thick 316/L SS bottom plate of 24-in. diameter. Beneath this, four custom feet were welded in place to minimize heat loss. The tubular component of the reservoir is a 24-in. NPS, Schedule 20,316/L SS pipe section, 37.5-in. long. A custom cap and flange to close the vessel were also fabricated of $3 / 4-i n .316$ SS plate. To minimize required preload to seal the cap, a Flexitallic 845 faced kammprofile gasket was utilized. The lower (wet) weld was applied from both sides to minimize areas where impurities could reside.

The reservoir was placed on a Triner EZ-Bar scale, model WB5000 (40 in.), and coupled to a TS-500SL reader. This reader was in turn coupled to the LabView system to output reservoir mass. Heat was applied to only the sides of the reservoir via three independently controlled heater zones: lower, mid, and upper. Each zone consisted of a controlling thermocouple, four AWH-102-080D heating tapes, and its own dedicated solid-state relays circuit controlled via the LabView system.

All feed-throughs were located in the reservoir top to minimize possible leakage. Molten salt was moved to and from the reservoir via a $1 / 2$-in. OD $316 \mathrm{SS}$ dip tube with the open end located $1 / 2$-in. from the bottom of the reservoir. A 1/4-in. type K Omega thermocouple to supply the LabView bulk temperature was located 13 in. from the bottom of the reservoir. A 2-in. flanged port was machined in the top to allow for salt addition and any future equipment to be tested. 

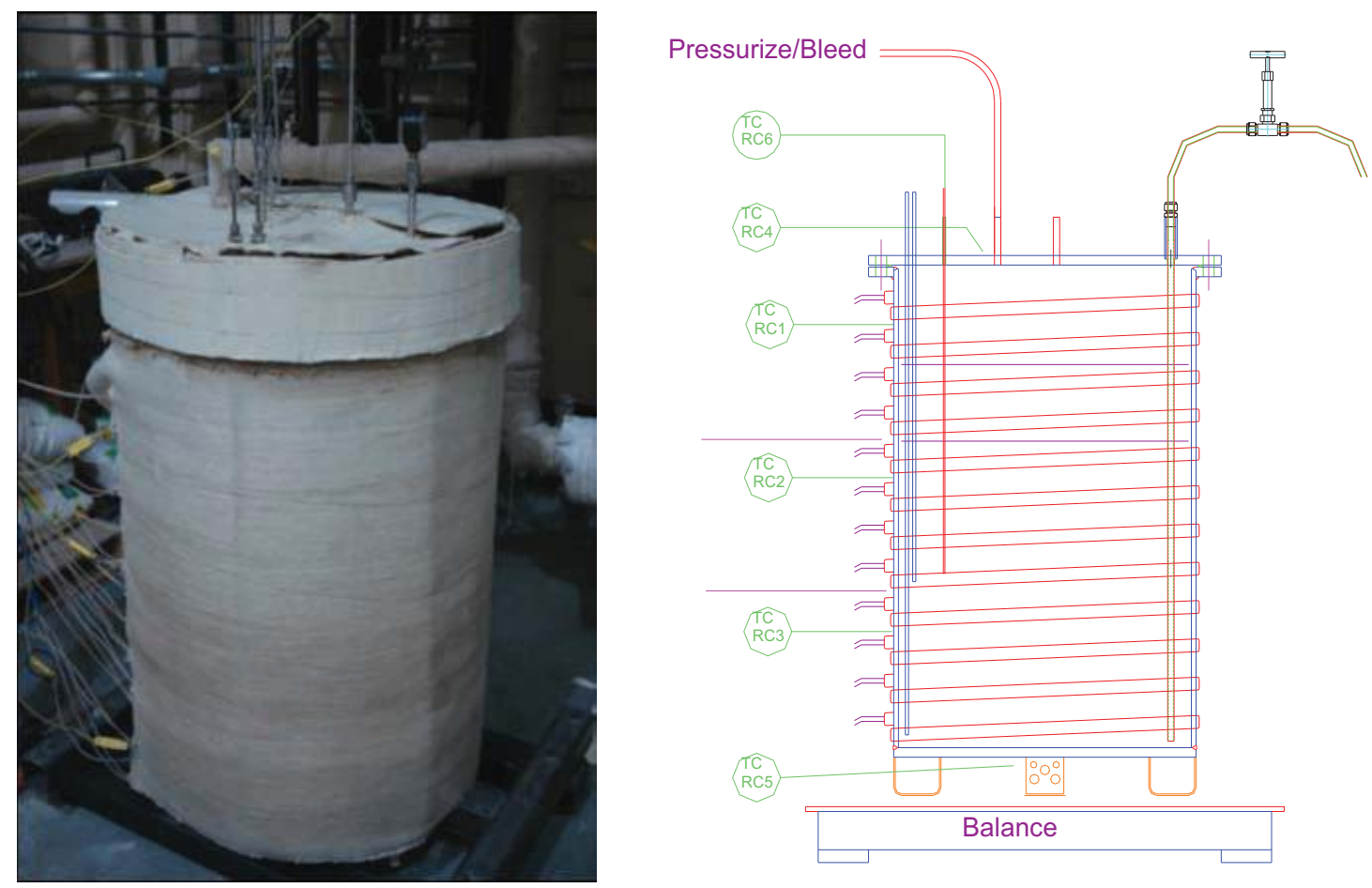

Figure 12. Reservoir and reservoir design.

Four $1 / 2$-in. Swagelok ports were located in the top. Two were utilized for the twin lances to determine density and level (as shown in Figure 12). A Rosemont model 3051S differential pressure transducer with a calibrated range of $0-250$ in. $\mathrm{H}_{2} 0$ was utilized for the level measurement. A Siemens model 7MF4432 differential pressure transducer with a measuring span of 2-60 mbar was utilized for the density measurement. The remaining two were for an overhead pressure measurement transducer and overhead gas supply/vent. A Rosemont model $3051 \mathrm{~T}$ pressure transducer with a calibrated range of 0-100 psig was utilized for the overhead gas pressure measurement. No adverse issues have been encountered with this system.

\section{Pump}

The pump for this system is a Nagle 1.5 -in. X 2-in. CWO-RS frame 95 , at a $3 \mathrm{ft}$ setting, Serial No. A8-1245. A search of available vendors limited the choice to this single manufacture due primarily to delivery time. The flow limits on the pump are 120gpm@15-ft head. This piece of equipment is a vertical cantilevered shaft pump, as shown in Figure 13, driven by a $7.5 \mathrm{hp}, 1,765 \mathrm{rpm}$, WEG inverter duty motor. The motor is powered by an ACTECH model 1475C, 480 Vac inverter, which is controlled via LabView.

All wetted parts on the pump are standard 316 SS. For this application, we requested the pump cover be made of 1-in. 316 SS plate, with two times the standard number of flange mount holes. The stock pumps are not provided to hold a sump pressure, which necessitated these and other changes. 


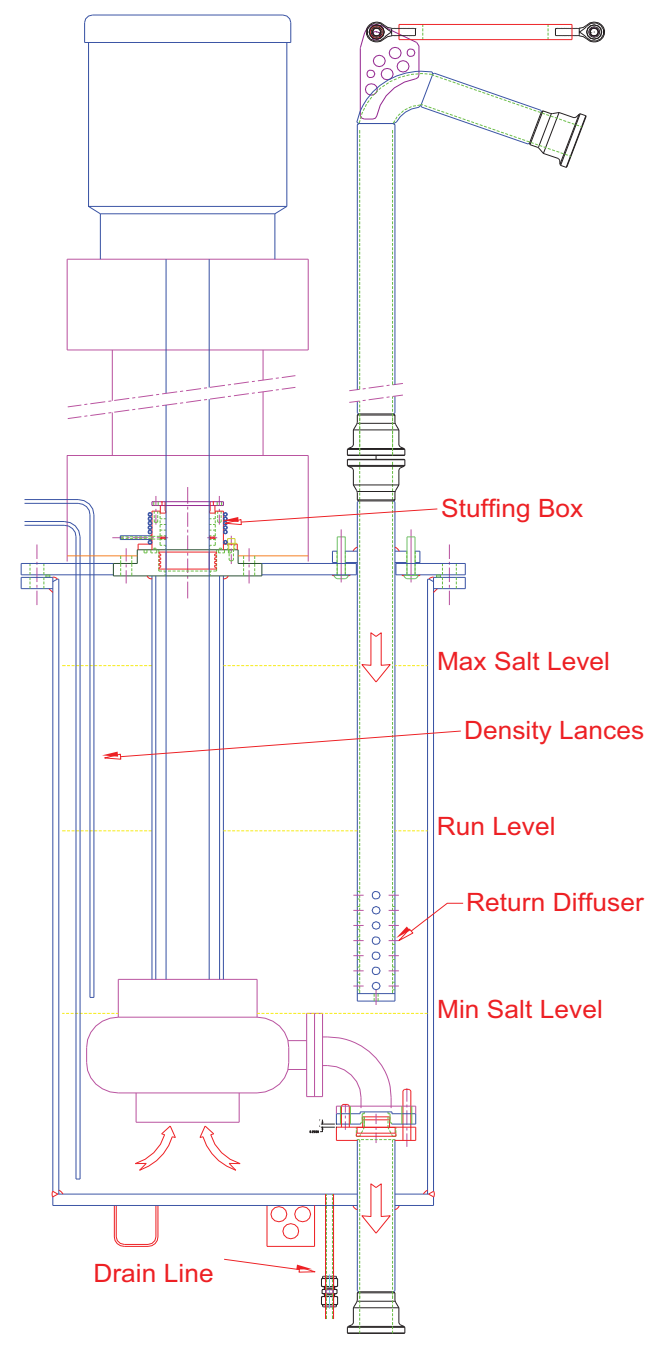

Figure 13. Pump.

The standard configuration for this pump is a vertical upward discharge. For this application, a vertical downward discharge was desired. To accommodate this change, the factory supplied the pump with an elbow aligned for downward discharge. The factory design did not allow for any differential expansion induced movement. An internal type slip coupler was designed and fabricated on site at UW to allow for this expected issue (as shown in Figure 14).

The pump was assembled at ground level before installation into the loop to check the effectiveness of the factory supplied labyrinth seal on the pump shaft. It was determined the seal would not hold enough pressure to allow for return transfer to the reservoir. A water cooled, five graphite cord, lantern ringed seal was designed, fabricated, and installed onsite at UW to allow the pump reservoir to hold the desired overhead pressure (as shown in Figure 15).

The pump sump was fabricated in the same fashion and materials as the reservoir. This sump was heated, controlled, and insulated in the same fashion as the reservoir.

Two feed-throughs were fabricated into the bottom plate of the sump. The first was the 2-in. discharge feeding from the pump to the heater. The second was a $1 / 2$-in. OD 316 SS drain line feeding into the heater to allow the salt below the pump intake to drain when the loop was emptied. 


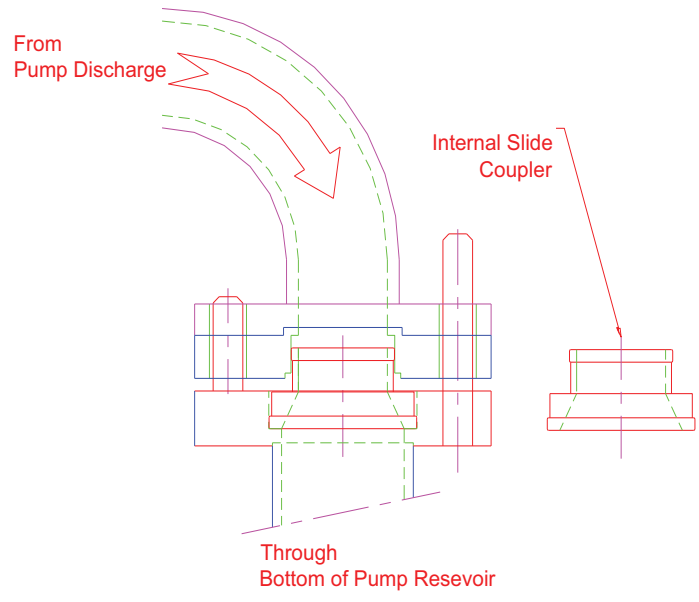

Figure 14. Slip coupler.

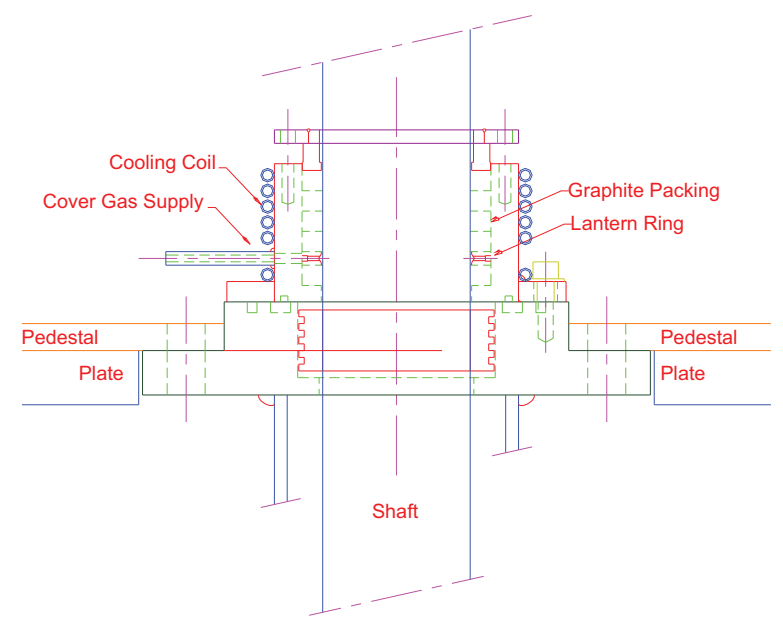

Figure 15. Shaft seal.

The return diffuser was fabricated of the same 2-in.NPS pipe as the general loop. A slip-on type flange was welded onto the return diffuser tube and this flange assembly was mated to a hole and studs in the pump cover to allow for easy removal. A cap with a $1 / 2$-in. diameter central hole (for drainage) was welded to the lower end of this diffuser. The bulk of the fluid exited radially from the diffuser through $28 \times 1 / 2$-in.-diameter holes, drilled radial, four per vertical location (equally spaced at 90-degree increments), on 1 -in. vertical centers.

Density/level lances were installed in the pump sump. These were identical to the lances in the reservoir, except with different lengths, which were modified to account for the differing heights of the vessels. These lances were measured with the same model pressure transducers as in the reservoir. An overhead gas pressure transducer was also installed in the sump with identical model pressure transducer as the reservoir. No adverse issues have been encountered with the pump.

\section{Heater}

The heater system for the large loop (as shown in Figure 16) is located directly below the pump. The fluid flows vertically downward from the pump into the inlet of the heater, then turns 90 degrees to horizontal, and enters the heating plenum. The fluid then flows vertically downward through the plenum, and turns 90 degrees to horizontal as it flows through the exit tube. Following that, the fluid turns vertical downward and enters the transfer tube below the heater. As the fluid flows through the plenum, it can receive heat from the three internal cartridge heaters and/or the external tape heaters with a total maximum power of 23 kilowatts. This power is modulated via 2 type $\mathrm{K}$ thermocouples inserted into the fluid: one in the entrance and one in the exit section.

The heater section is sealed to the general loop via Grayloc closures. The Graylocs, inlet tube, and exit tube are all 2-in. NPS, Schedule 40,316/L SS. The plenum is fabricated of 316/L SS tube 3.75-in. OD by 3.25 -in. ID by 60 -in. long. Three tubular platens are located inside the plenum. These platens are 316/L SS 1-in. NPS Schedule 10 pipe, with the lower end sealed via a welded $1 / 4$-in. disc of the same material. The upper end of the platens are inserted through tight fitting holes, and welded to the top cap of the plenum, leaving the inside of this pipe exposed to atmosphere. At two different vertical locations inside the plenum, the platens are held in proper location via welded locating rings. The bottom cap of the plenum is plain with no features. 


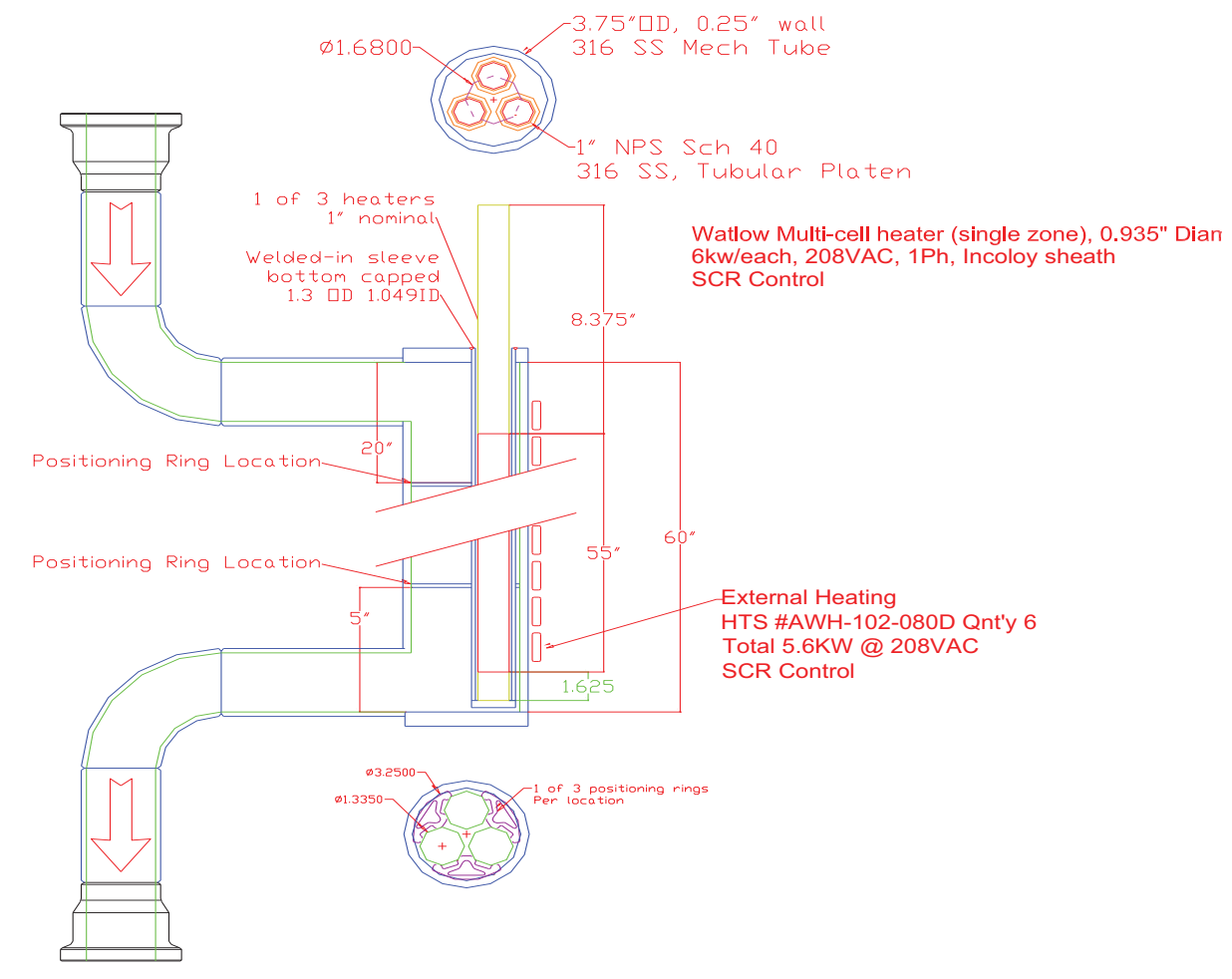

Figure 16. Heater system for large loop.

One $6 \mathrm{~kW}$, Watlow multi-cell heater $(\mathrm{P} / \mathrm{N}$ 9703) was installed in each platen. These heaters were $208 \mathrm{Vac}$, single phase, Incoloy sheathed, 0.935-in. nominal diameter, with an overall length of 65 in. They were lubricated (prior to insertion) with Chromolox HTRC to facilitate extraction if necessary. The power to these heaters was controlled via Control Concepts Inc. SCR Power Controller, Model \#1027A.

Six AWH-102-080D 936 Watt tape heaters were wrapped in a tight spiral fashion on the outside of the plenum. These heaters could apply a maximum of $936 \mathrm{~W}$ each at $208 \mathrm{Vac}$. The external tape heaters were controlled by Control Concepts Inc. SCR Power Controller, Model \#1021A. These heaters were temperature limited by a centrally located thermocouple welded directly to the outside of the plenum. No adverse issues have been encountered with the heater.

\section{Test Section}

The tubular body of the test section was constructed of 2-in. NPS, Schedule 40 316/L SS pipe. The straight, uniform length of the test section was 255.3-in. The flow came from the throttling valve at an angle of 2 degrees below horizontal, entered the lower (long radius, Schedule 40) custom machined elbow, and then turned vertically upward through the large loop test section (as shown in Figure 17). At the top of the section, the flow exited through a custom machined long radius, Schedule 40 elbow continuing to the flow meter at an angle of 20 degrees above horizontal. The internal temperature of the fluid in the test section was measured at six locations. In the entrance and exit elbows, a port was machined to locate the two resistance temperature devices (RTD) at TS1 and TS6. Both were Hart Scientific Model 5626, 12-in. in length, with a diameter of 3/8 in. Both were read by dedicated Hewlett Packard multimeters, Model 3458A, which in turn communicated their status to the LabView system. The tips of both RTDs were located 2.4-in. inside the ends of the test section (125.2-in. from the centerline of the test section). This mounting provided a wetted length of 5.25-in. The RTDs were sealed to the test section by a Swagelok SS-810-6-6BT swaged onto a $1 / 2$-in. OD 316 SS tubular stand-off. 
To acquire usable pipe wall temperatures, thermocouples were directly welded to outside of the test section. These thermocouples were installed in groups of three at six distinct vertical locations on the test section (see Figure 17). Each group had one thermocouple welded under the heater location, one applied under the cooling tube, and one between the heater and cooling tube. With these thermocouples, an average pipe wall temperature (and variance from) can be calculated. The test section performed as expected with heat fluxes on the order of $300 \mathrm{~W} /$ linear foot.

The internal temperature of the fluid was also measured by thermocouples at four locations along the length of the test section. These thermocouples were installed with the tip located 0.2625-in. inside the inner pipe wall. All four thermocouples were Omega type K model HKMQIN-125U-12, 1/8-in. diameter, 12-in. long, and ungrounded. The thermocouples were sealed to the test section by a Swagelok SS-400-6-2BT and swaged onto a $1 / 4$-in. OD 316 SS tubular stand-off.

The test section was trace-heated with 12

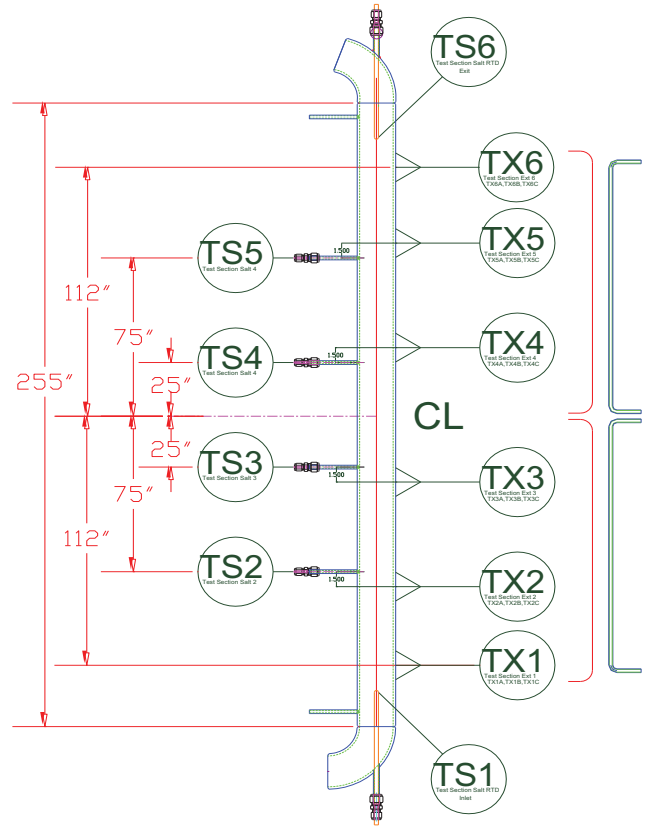

Figure 17. Large loop test section. AWH052 100DM tape heaters. These were divided into an upper and lower zone, split at the center of the test section, each utilizing six of the 10-ft-long heaters. A zone consisted of the six heaters directly applied along the axis of the pipe, equally spaced about the circumference. All heater leads were located at the center line of the test section.

A 1/4-in. layer of Kaowool S, 8 pcf, was firmly fixed over these heaters. The cooling tubes were installed over this Kaowool.

The cooling system consisted of twelve $1 / 4$ in. OD X 0.035 in. wall 304 SS tubes. These tubes were divided into an upper and lower zone, with 6 tubes in each. Each tube was placed along the axis of the test section, over the Kaowool, in the area between the heaters. Each tube had 116.5-in. of length in contact with the Kaowool. The cooling zones were centered vertically with respect to the centerline of the test section. The flow was in series, travelling through a lower tube, then through the upper tube directly above it. The tubes were vertically staggered to maintain uniform cooling where the upper and lower zones met.

The chilled process water was supplied to this system at approximately $12^{\circ} \mathrm{C}$ and $60 \mathrm{psig}$, with a minimal differential pressure between supply and return. To attain our desired flow a G\&L 1551DK40, 3.5-in. diameter impeller pump was installed in the supply line. The chilled water exited the pump, flowed through a filter to remove impurities, through a Foxboro, $1 / 2$-in. NPS, model CFS10-055CFNN coriolis flow meter, and into the top of the lower cooling manifold (see Figure 18).

The chilled water exited the lower manifold through six 1/4-in. OD X .035 wall tubes of identical length, which in turn were coupled to the six lower cooling tubes. The flow proceeded vertically upward to the top end of the lower cooling tubes, where six identical length coupling tubes connected the flow to the bottom of the upper cooling tubes. The flow then proceeded to the upper manifold, where it was returned to the building chilled water system (see Figure 19). 


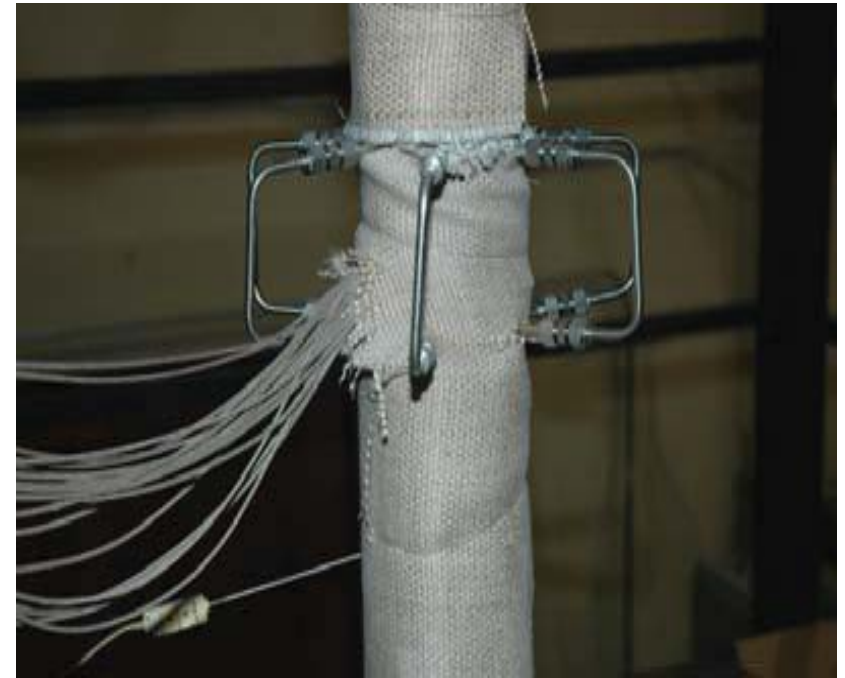

Figure 18. Chilled water coupling tubes.

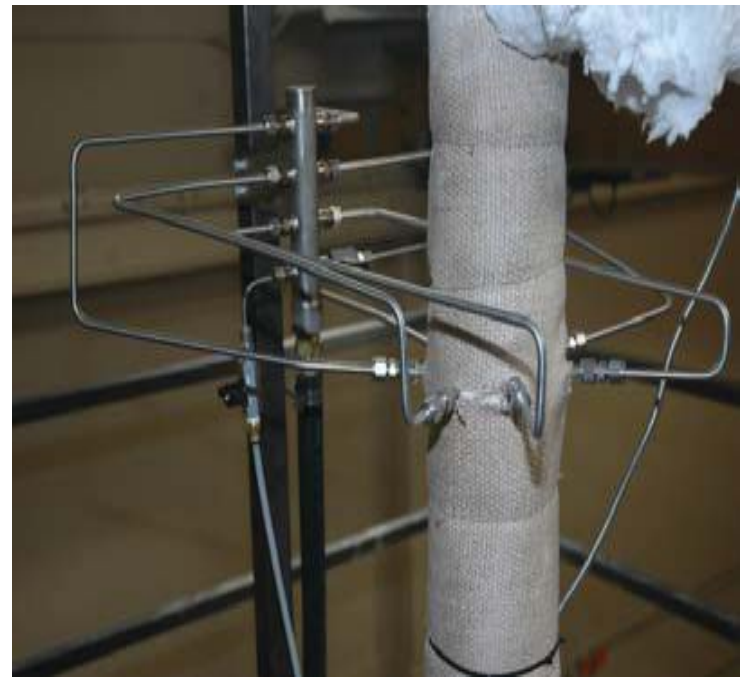

Figure 19. Lower chilled water manifold.

To record cooling water temperature data, Omega type K model HKMQIN-125U-12, 1/8-in. diameter, 12-in. length, ungrounded thermocouples were installed in the upper and lower manifolds. This installation was designed to enable the upper manifold thermocouple to be removed and installed in the lower manifold (without removing wires) to enable a side by side calibration.

Two layers of 0.2-in. thick Pyrogel XT were wrapped over the cooling tubes. This in turn was covered by a single layer of high temperature silica fabric (density of $40 \mathrm{oz} / \mathrm{sq} \mathrm{yd}$ ). The test section has performed as expected with heat fluxes on the order of $300 \mathrm{~W} /$ linear foot.

\section{Flow Meter}

To accurately determine the flow rate in this test loop, a 2-in. NPS Panametrics Ultrasonic Liquid Flow meter was acquired. It is a model DF868, reader Serial No. 7541, flow cell serial no. 3125. Before operation, the meter reader was returned to the factory to install an additional input channel for a second flow cell, as well as additional analog output channels. The pre-manufactured spool piece was received without closures on the process ends, as requested. Grayloc butt weld hubs of the appropriate size were TIG welded onto the spool when received. The spool piece consists of a section of 2-in. NPS pipe with 1.5-in. NPS standoffs welded over ports in the pipe at an angle of 30 degrees to the pipe axis. The spool pipe itself is of sufficient length to provide 10 diameters of straight pipe upstream from the ultrasonic traverse path and five diameters downstream. The standoffs terminate with $150 \#$ Schedule 80 pipe flanges and because of the high process fluid temperatures, the ultrasonic transducers are mounted on long BWT buffers that extend into the standoffs.

A second spool piece was acquired, Serial No. 3543, and the Vogt globe valve was removed from the loop to create an installation position for the spool. Grayloc hubs were TIG welded to the new spool just as with the first and the Grayloc at the bottom of the test section was relocated to accommodate the spool. The drain line to the reservoir was relocated from the valve body to the drain port at the bottom of the test section next to the RTD. 


\section{Nitrate Salt Materials Loop}

A schematic illustration of the loop is shown in Figure 20. All wetted parts of the loop are constructed with $316 \mathrm{SS}$. The pump is situated on top of the loop to allow draining of the loop system for restart and to allow an access port to the loop while in operation. The level of the fluid is usually kept below 1.5-in. from the top flange of the pump reservoir. The pump is of a sump design and discharges downward into the loop. A valve situated below the exit of the pump allows pressure and flow rate control. The pump motor is controlled by a frequency inverter, which allows adjustment of the rpm of the motor, and thus the pumping speed and the velocity in the loop. Combined with the main loop valve, this allows for precise control of the flow rate and pressure drop in the loop.

Following the loop circuit around in a counter-clockwise direction (flow direction), the next major feature of the loop is the main heater. The flow enters the manifold of the heater from the bottom. The manifold then splits into 7 parallel channels, each with a 0.71 -in. diameter $9 \mathrm{~kW}$ maximum power Watlow immersion heater. The immersion heater is inserted into a 0.884 -in. ID tube, leaving a flow gap of 0.087 -in., which is necessary to increase the velocity of the fluid and increase the heat transfer rate. A schematic of the heater assembly is shown in Figure 20. The total power is $63 \mathrm{~kW}$; however this is slightly de-rated as the operating temperature is increased.

The main heater assembly schematic is shown in Figure 21. The entire heater assembly is set with an incline 10-degree angle to allow proper drainage of the liquid salt from the heater assembly, such that it could be removed from the loop via the Swagelok compression fittings. The heater is controlled by a LabView code and a three phase 208 V SCR circuit, which allows PID control of the heater based on a set exit temperature or to be operated with a manual constant voltage (constant power) to the heater elements. Each of the seven heating elements can be electrically isolated such that the heater can be run with any number of heating elements, thus if any one element fails total heating capacity is not lost.

The fluid exits the main heater into a similar manifold and then is directed upward into the 1 in. diameter tube of the main loop. From the heater, the fluid enters the hot leg test section of the materials loop. In the start-up/shut-down tests, a tube replaces the sample holder and is connected via the Swagelok fittings. The fluid then enters the cooling portion of the loop. This section is again constructed of 1-in. Schedule 40 pipe, but has copper cooling coils wrapped around the outer circumference of the pipe. Cooling water from the building chilled water system flows into a manifold and then enters into the copper cooling coils. After exiting the cooling section, the fluid enters the upper materials testing location (this is the cold leg of the loop when running materials samples). This section was replaced with an ultrasonic flow meter (Krohne model number UFS3000F). This is an inline 1-in. diameter ultrasonic flow meter, which has a temperature limit of $230^{\circ} \mathrm{C}$. This flow meter was desirable because it allows for accurate measurements of the flow rate and allows us to obtain pump curves for the liquid salt. For higher temperature operation, this flow meter could be replaced with a Foxboro vortex flow meter with a temperature limit of $450^{\circ} \mathrm{C}$; however, the accuracy at low flow rates is not sufficient. The ultrasonic flow meter also had the added advantage that it measures the fluid's sound speed. After the fluid leaves the cold leg (flow meter) section, it dumps back into the top of the pump reservoir though a flow dispersal nozzle. 


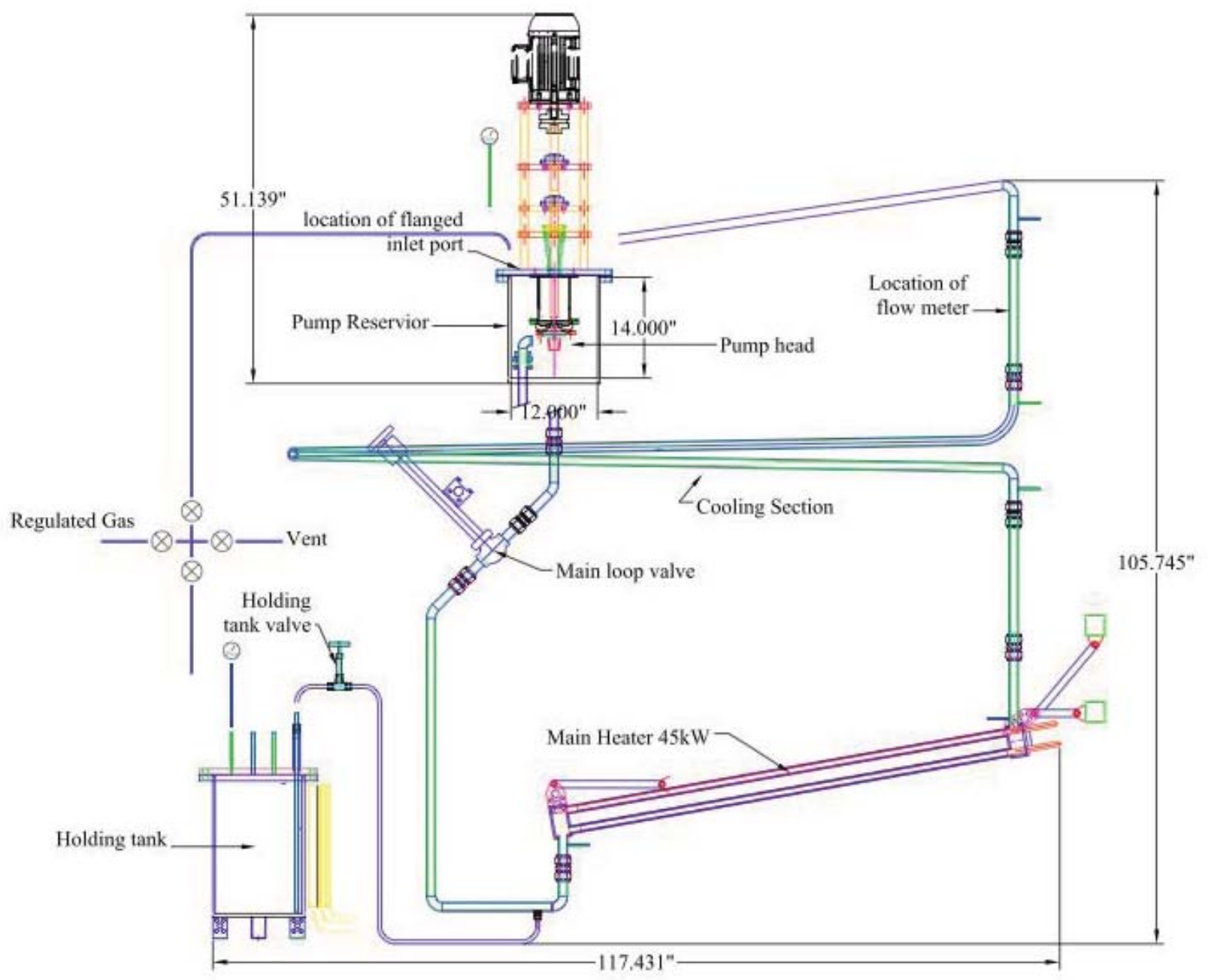

Figure 20. Schematic illustration of materials loop used for salt start-up and shut-down tests.

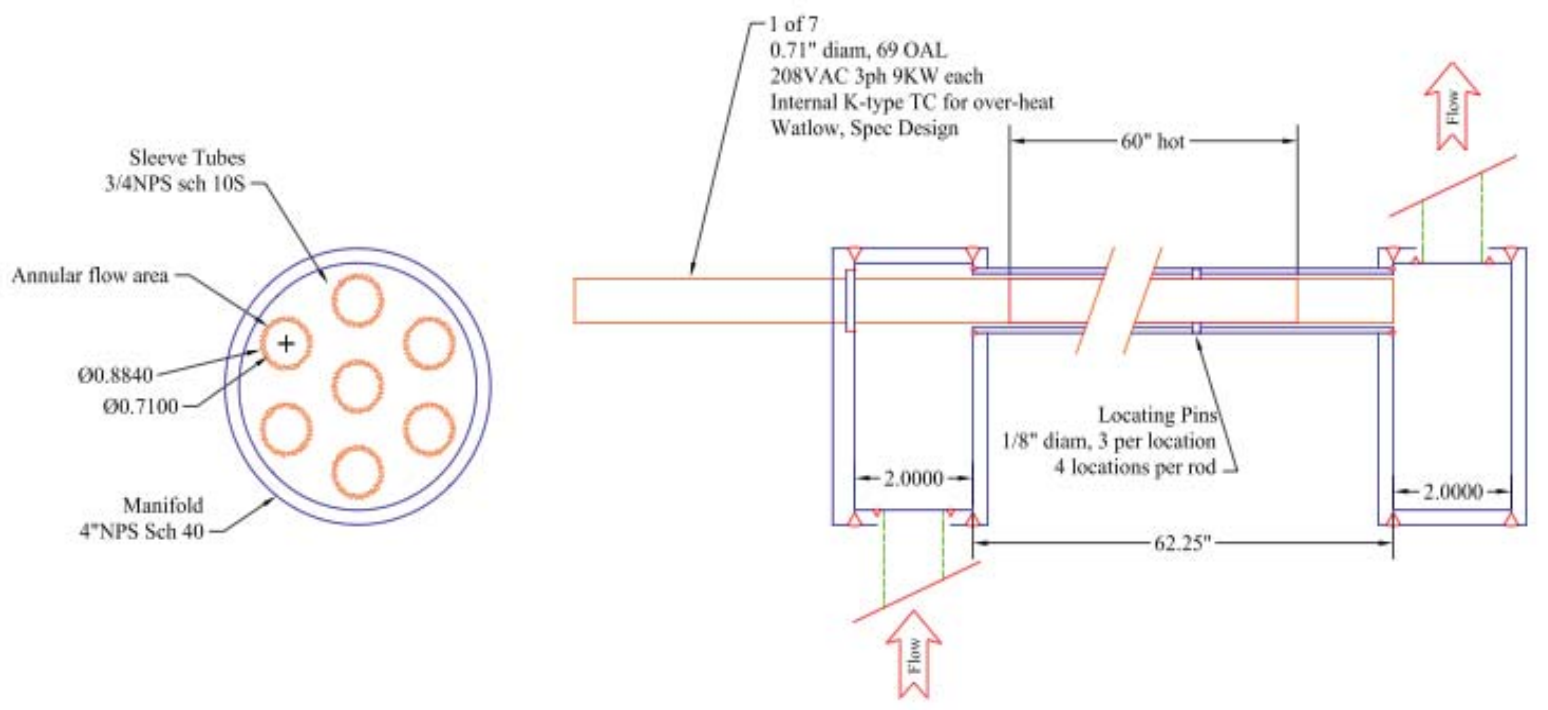

Figure 21. Schematic of the main heater assembly. 
Figures 22 and 23 show the nitrate salt materials test loop and the pump, which is modified with a mesh screen on the inlet to prevent $\mathrm{KNO}_{3}$ and $\mathrm{NaNO}_{3}$ prills from entering the pump cavity before dissolution. The pump return discharge fluid dispersal nozzle and the inlet access port used to fill the pump reservoir with the solid salt constituents is seen as well.

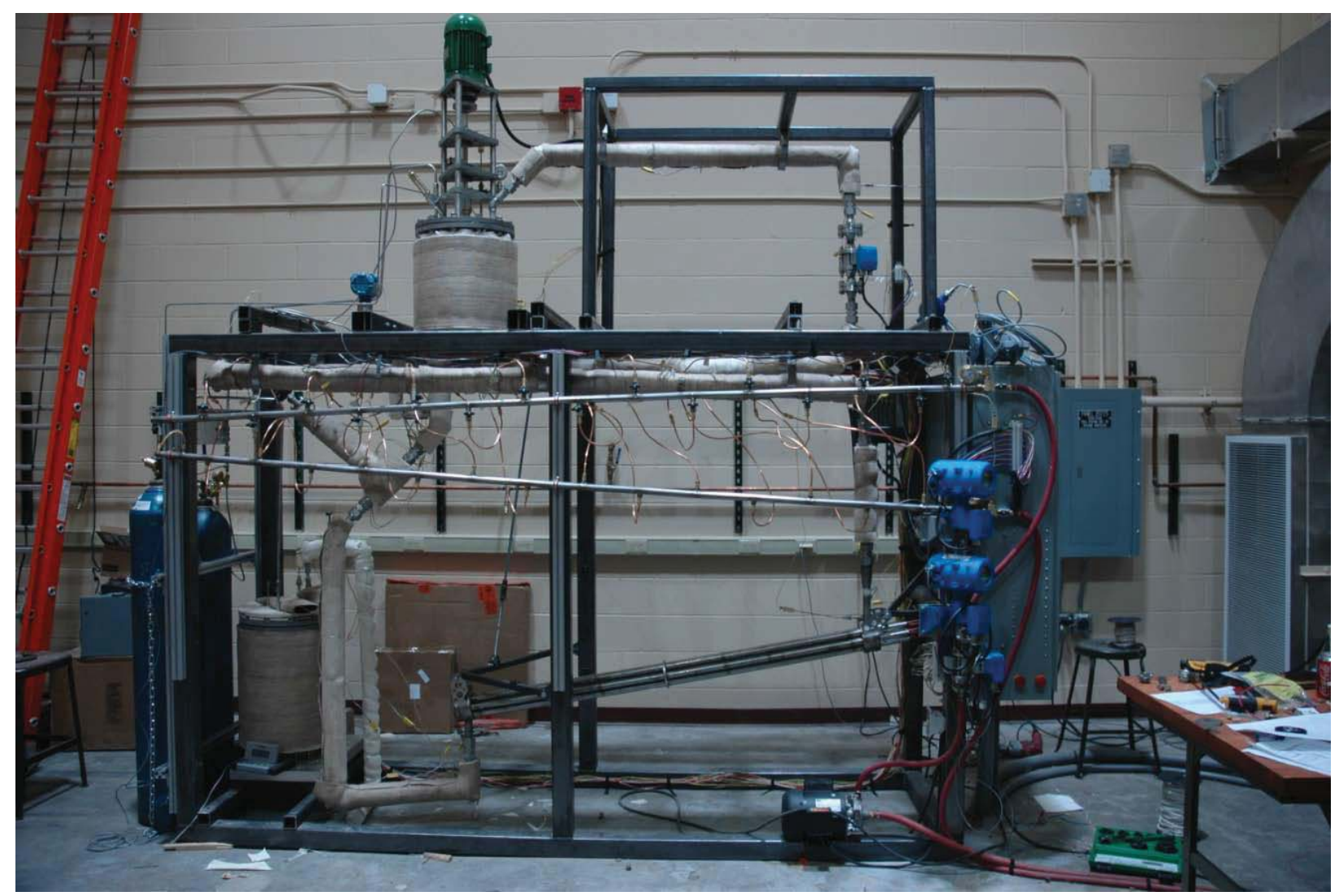

Figure 22. Liquid salt materials test loop used to perform the aqueous salt solution start-up. 


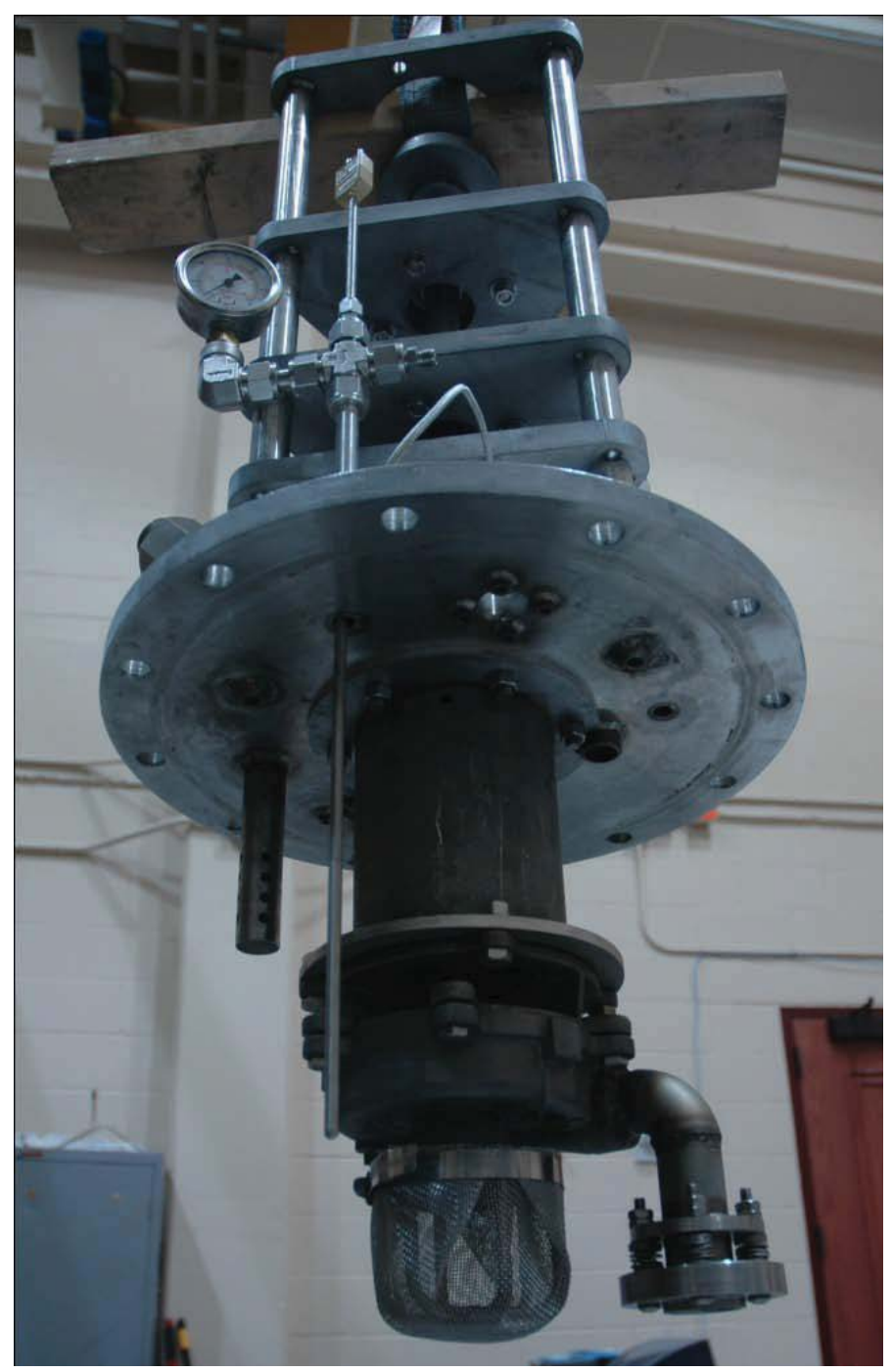

Figure 23. Modified pump to prevent $\mathrm{KNO} 3$ and NaNO3 prills from entering the pump cavity before dissolution.

\subsection{Modeling of Salt Properties}

In determining the phase diagram of a salt mixture, it is necessary to know the Gibbs energy of each phase in the system (Ozeryanaya, 1985; Ozeryanaya et al., 1975). The Gibbs energy of the system is then used to determine under what conditions the two phases are in equilibrium (Anderson et al., 2010).

With knowledge of the Gibbs energy of the liquid and solid phases, computational techniques are utilized to determine the liquidus and solidus lines for different salt mixtures by minimization of the Gibbs energy of the system. The equilibrium distribution is calculated by setting:

$$
\partial\left(G / \partial n_{A B}\right)_{n_{A}, n_{B}}=0
$$


The equilibrium pair fractions can then be computed by the following equations:

$$
\begin{aligned}
X_{A B}^{2} /\left(X_{A A} X_{B B}\right) & =4 \exp \left(-\Delta g_{A B} / R T\right) \\
1 & =X_{A A}+X_{B B}+X_{A B} \\
X_{A} & =\frac{\left(2 n_{A A}+n_{A B}\right) / Z_{A}}{\left[\left(2 n_{A A}+n_{A B}\right) / Z_{A}+\left(2 n_{B B}+n_{A B}\right) / Z_{B}\right]} .
\end{aligned}
$$

Using the site fractions evaluated from $\Delta \mathrm{gAB}$, a linear expansion is used to model $\Delta \mathrm{g} A \mathrm{~B}$ as a function of the pair fractions. This information of the short range order of the salt can then be used in modeling other properties, such as specific heat, density, viscosity, conductivity, and adiabatic compressibility (Anderson et al., 2010). 


\section{ISSUES AND RECOMMENDATIONS}

The existing data, as a whole, is insufficient to serve as a basis for reliable selection of containment materials for compatibility with molten salts. The main technical development needed for use of molten salts at high temperatures is the material's performance; understanding the role of corrosion and preventing degradation of materials are the key requirements (Delcul et al., 2002). The available FLiNaK studies are limited to the recent work of Kondo, et al. (2009), Olson (2009), Sridharan (2009), and Anderson, et al. (2010) at the University of Wisconsin, and the loop tests at ORNL. The Olson and Sridharan work involved a good selection of alloys, but all but one test were performed in carbon crucibles, which enhanced the corrosion rate substantially by galvanic corrosion or by a dissolution/ deposition mechanism that involved carburization. The molten salt composition is probably a key factor in corrosion kinetics and grain boundary attack; it is not clear how well data from dissimilar salts can be extrapolated to other molten salt systems. From the limited available corrosion studies, it is not clear that highly pure salts mixtures are absolutely necessary for optimum corrosion resistance, or whether there is a threshold concentration (oxidation potential) in the various salts above which corrosion becomes problematic. Studies considering redox potential control have been conducted and shown to have some promising effects; however, further detailed studies are necessary to study proximity and migration of redox agents in molten salt systems.

\subsection{Issues}

\subsubsection{Fluoride and Chloride Interactions}

For the FLiNaK tests, several alloys were tested in graphite crucibles at UW. Graphite was chosen as the container material, so that several different alloys could be studied and compared on the same basis. Further, it was recommended by ORNL as a suitable material crucible for initial testing with the knowledge that there would be some galvanic increase in corrsosion. Graphite is very resistant to attack in molten fluoride salts, but was found to significantly accelerate the corrosion of alloys being tested because of its cathodic nature. Tests were also conducted using $\mathrm{KCl}-\mathrm{MgCl}_{2}$ and $\mathrm{FLiNaK}$ with $800 \mathrm{H}$ samples in both graphite and $800 \mathrm{H}$ systems for 500 hours to allow a direct comparison of the corrosiveness of KCL-MgCl2 and FLiNaK in the graphite and in the alloy containers. In essence, the graphite crucible acted as a cathode with respect to the more anodic test alloys and showed two orders of magnitude increase in corrosion, which had not been known previously. An interaction with graphite has also been seen by others in other molten salts systems where there was not direct contact with the alloys and the graphite. As mentioned earlier, graphite was chosen for a ranking of the alloys and to investigate the corrosion mechanisms. The measured corrosion is electrochemical or accelerated corrosion and effectively allowed a 500 hour to be used to study corrosion mechanisms that would have taken much longer in alloy crucibles.

\subsubsection{Chromium}

Chromium in the alloy is a concern in a FLiNaK heat transfer system because of its propensity to readily dissolve in molten fluoride salts. If nickel crucibles were used for all tests, there would have been mass transport because of the activity difference, i.e., chromium would have transported from the high chromium alloys to the low chromium alloys. This type of mass transfer was seen in ORNL tests where a Haynes alloy was accidentally introduced into a Hastelloy $\mathrm{N}$ harp loop. Cobalt and chromium from the Haynes alloy no. 25 was depleted from the Haynes alloy and deposited onto the Hastelloy-N sample. Niplating by itself may not be an effective long-term protective strategy to prevent chromium loss at the temperatures of interest $\left(\sim 850^{\circ} \mathrm{C}\right)$ in oxidizing salt conditions. For NGNP heat transfer applications, Ni cladding of pipes may be a viable option or use of a constant alloy, such as $800 \mathrm{H}$, for all fittings and connections may limit corrosion enough to be economical. Diffusion barriers have been in wide use in industry for diffusion prevention, and could likely be readily applied, but need more research. Even in the individual alloy samples from the graphite crucible tests (for specific alloys like Haynes 230, Hastelloy- 
$\mathrm{X}$, and Hastelloy-N), it appears that chromium-lean phases where less prone to corrosion, whereas chromium rich phases (grain boundary chromium carbides, and chromium rich matrix) were prone to corrosion.

\subsubsection{Heat Transfer Issues}

- For the molten salt loop to operate at low flow rates, and correspondingly low pressure drops, the number of commercial instrumentation options that can be utilized is limited.

- Commercially available flow meters can operate at higher temperatures but require higher flow rates; the most promising is the ultrasonic flow meters.

- Specialty commercial pumps can be fabricated for high temperature molten salts, but are expensive and have long lead times. Low mass flow rate pumps in general that can operate at high temperature are specialty items and need to be designed and manufactured to the loop's desired goals.

- Commercially available pressure sensors had a high level of error to measure low pressure differences. NaK filled systems can be made commercially if there is a sufficient demand from them.

- Most ternary and higher order systems of salt mixtures do not have much experimental data available for the determination of density, viscosity, thermal conductivity, and stability data for higher temperatures.

- More empirical models need to be developed and validated to predict properties of these higher order salt systems to narrow down potential salts and their compositions of interest for applications without needing to experimentally determine values for the possible composition space.

- Pure molten salts are nearly transparent to infrared radiation allowing significant heat transfer to occur by radiation and tendency of the salts to naturally convect heat to the cold surface increasing the rate of heat transfer from hot to cold regions. These two effects cause a large source of error in the measurement of the thermal conductivity of molten salts. Also, the absorption effects of trace contaminant species is not known and could affect the radiative properties.

\subsection{Recommendation and Future Work}

A few areas have been identified, which need to be addressed in order to make liquid salt research a viable technology for nuclear heat transport.

\subsubsection{Modeling of Salt Chemistry and Properties}

- Continuation of research on the modeling approaches for the liquid salts. Quasi-chemical models should be expanded to allow estimations of the salt properties of higher order salt systems, such as zirconium additions to fluorides or additions of $\mathrm{Ca}$ to the nitrate mixtures. Also of interest may be carbonate salts.

- Improvements to the models to allow better predictions of some of the more difficult to measure properties, such as thermal conductivity and viscosity are needed along with empirical data. This would involve both chemical models and perhaps some molecular dynamics models to completely understand the interaction potentials.

- Modeling efforts to understand the transport of certain species and to start to understand the effect of redox control and chemistry within the salt should be continued. This should include understanding the effects of multi-component systems and species transport.

- Modeling should also be extended to help to understand the corrosion behavior that is observed in the experiments and models developed to predict the lifetime of components based on the empirical data. This requires extrapolation of short time tests to long term corrosion and may require more detailed modeling to help extend the mechanisms for the corrosion to allow this extrapolation. Models to 
understand the acceleration effect of the graphite are needed and may allow expedited tests for pure alloy systems.

\subsubsection{Property measurements}

- With the development of new salts, physical properties will have to be determined and compared to the models.

- Increased accuracy of the measurements of some of the key thermo-physical properties of some of the most promising salts is needed. The thermal conductivity is a difficult measurement and is important in determining heat flows in liquid salt systems. Also, the heat capacity and viscosity of many of the salts are only known to within $20 \%$; this limits the accuracy on flow meters and other thermal hydraulic predictions. As engineering models become more mature, increased accuracy in these thermo-physical quantities will be needed.

- There is little known about the effects of contaminants in the salts. This includes the effects on corrosion but also the absorption and optical transmission properties of the salts. At high temperatures this is important due to thermal radiation.

- Measurements of salt purity and different methods to prepare salts to the levels of purity needed for NGNP heat transfer and AHTR applications is needed. Also methods for initial cleaning of component surface to mitigate corrosion and lower salt contamination during service are needed. Commercial grade salts need to be studied and determine the appropriate cleaning processes.

\subsubsection{Materials Studies}

- Continuation of materials corrosion studies in both static and dynamic system to estimate long-term corrosion rates and understand corrosion mechanisms.

- Test containment (crucible) material plays an important role in dictating corrosion rates; corrosion experiments should be performed in the same crucible alloy as the alloy being tested.

- Experiments to mitigate materials corrosion by controlling the redox potential of the salt (for example, by the addition of $\mathrm{Zr}$ to FLiNaK and Be to FLiBe).

- Corrosion tests should also be performed in systems with multiple alloys that may be present in the reactor systems to understand synergistic effects of the simultaneous presence of multiple alloys on the individual corrosion rates.

- Determine the saturation solubility as a function of temperature for several key transition metals in the four salt systems of interest. Correlate the effect of the magnitude of saturation solubility gradients in a system with extent of corrosion by testing a selected set of chromium alloys in a temperature gradient system (loop) as a function of temperature gradient.

- A big issue is the welded area of tubes. It will be important to start to study the effects molten salts on the heat-affected zone of the weld regions and determine if there is excessive corrosion in these areas and/or if there is galvanic corrosion between the weld and the base material.

- Coatings have been found to significantly reduce the corrosion rates; in particular Ni, C, or Mo coatings seem to have considerable potential. Research is needed to test these coatings under different conditions and to develop methods for ensuring the stability of the coating and coating materials after welding.

- $\quad$ Since Ni-plating seems to be very promising for applications in molten fluoride salts, further optimization of Ni-plating microstructure to improve its efficacy would be beneficial; experimental programs on deposition of Ni-plating on the inside surfaces of long tubes. 
- The cation chemistry (iron, chromium, etc.) of the salt will continually change during operation due to dissolution of elements from the alloy into the salt; therefore, development of commercial systems for on-line monitoring of corrosion base on principles of electrochemistry are required.

- Effects of flow-assisted corrosion needs to be studied both from the standpoint of material lost to corrosion, but also dissolution of material in the hot section and its plate-out in the colder sections of the system.

- It is recommended that the compatibility of the potential high temperature piping alloy with the potential heat exchanger with pyrolytic carbon and silicon carbide $(\mathrm{PyC} / \mathrm{SiC})$ coated $\mathrm{C} / \mathrm{SiSiC}$ composite material be investigated in future.

- Test a series of welded high-chromium alloy coupons with variations in the severity of the heataffected zone and development of chromium carbide precipitates, to determine whether localized variations in alloy composition and carbide formation can induce localized galvanic corrosion that could impact the physical integrity of the alloy.

- Determine the corrosion rates as a function of alloy composition with respect to chromium and carbon, to define better the 'sweet spot' for chromium and $\mathrm{C}$ content, independent of galvanic or differential solubility effects.

\subsubsection{Thermal Hydraulics}

- The heat transfer coefficients for most salts are known to an accuracy of $20 \%$ in the turbulent regime. There is however little data in the transition and laminar regimes. Increased accuracy and modification of the Nusselt correlations for the salts are needed across the potential operating regions.

- As the temperatures are increased to above $600^{\circ} \mathrm{C}$, radiation heat transfer becomes important and the absorption data as a function of wave length is needed. Also, measurements of the heat transfer under these conditions are needed.

- More complete designs of heat exchangers are needed and studies to determine the use of compact heat exchangers for liquid salt systems area needed. This includes examining high temperature brazed heat exchangers and diffusion bonded heat exchangers. This needs to be done both at the commercial and the laboratory scale.

- Determination of the clogging potential of the salts, which can drastically reduce the diameter for the heat exchanger tubes must be studied. This is however coupled with both the materials corrosion and the product transport.

- The design of flow meters, pressure transducers, valves, seals and pumps need to be studied in more depth for commercial scale systems.

- Operational issues during start-up, shutdown, and steady state operation need to be determined, which includes issues with freezing salt in pipes and re-melting. Necessary trace heating, etc.

- Safety issues with regard to liquid salt release should be studied. Interactions of the salt with insulation, concrete, water, and hydrocarbons needs to be studied to determine potential safety hazards associated with the salts. Also, off-gassing of the salts especially those containing fluorine or beryllium need to be more fully understood. 


\section{REFERENCES}

Ambrosek, J. "Molten Chloride Salts for Heat Transfer in Nuclear Systems," Ph.D. Prelim Proposal, University of Wisconsin-Madison, Madison, WI, USA, 2010.

Anderson, M., et al., 2010, "University of Wisconsin-Madison Molten Salt Program- Experiments and Lessons Learned," March 2010.

Davis, C., 2005, "Implementation of molten salt properties into RELAP5-3D/ATHENA," INEEL/EXT-05-02658, Idaho National Laboratory, January 2005.

Delcul, G. D., D. F. Williams, L. M. Toth, and J. Caja, 2002, “ Redox Potential of Novel Electrochemical Buffers Useful for Corrosion Prevention in Molten Fluorides," Procedings of $13^{\text {th }}$ Int. Symp. Molten Salts, $201^{\text {st }}$ Mtg. Electrochemical Society, Philadelphia, Pennsylvania, May 12-17, 2002.

Forsberg, C. W., P. F. Peterson, P. S. Pickard, 2003, "Molten Salt Cooled Advanced High Temperature Reactor For Production of Hydrogen and Electricity," Nuclear Technology, Vol. 144, p. 289.

Grimes, W. R., E. G. Bohlmann, A. S. Meyer, and J. M. Dale, 1972, "Fuel can Coolant Chemistry", Chapter 5 in M. W. Rosenthal, P. N. Haubenreich, and R. B. Briggs, The Development Status of Molten-Salt Breeder Reactors, ORNL-4812, Oak Ridge National Laboratory, Oak Ridge, TN, August 1972.

Heine, D., F. Heess, and D. Steiner, 1982, Investigation of Latent Heat Storage Materials in the Medium and High Temperature Range, PB82-259896, Commission of European Communities, Luxembourg, Institut fur Kerntechnik and Energieumwandlung, Stuttgart, Germany, August 1982; translated from the German, Untersuchung von Mittel- und Hochtemperatur-Latentwaermespeicher-Materielen, BMFT-FB-T 81-149, EUR 7062 DE, August 1981.

Ingersoll, D. T., C. W. Forsberg, and P. E. MacDonald, 2007, Trade Studies on the Liquid-Salt-Cooled Very High-Temperature Reactor: Fiscal Year 2006 Progress Report, ORNL/TM-2006/140, Oak Ridge National Laboratory, Oak Ridge, TN, February 2007.

INL, 2007, Next Generation Nuclear Plant Pre-Conceptual Design Report, INL/EXT-07-12967, Idaho National Laboratory, Rev 1, November 2007.

Kane, R., 2003, "Molten Salt Corrosion," in ASM Handbook: Corrosion-Fundamentals, Testing, and Protection, Vol 13A, S. Cramer and B. Covino, editors, ASM International, 2003, pp 216-219.

Kondo, M., T. Nagasaka, T. Muroga, A. Sagara, N. Noda, Q. Xu, D. Ninomiya, N. Masaru, A. Suzuki, T. Terai, 2009, "High Preformance Corrosion Resistance of Nickel-Based Alloys in Molten Salt Flibe," Fusion Science and Technology, Vol. 56, pp. 190-194.

Lovering, D. G., and R. J. Gale, 1983, Molten Salt Techniques, Vol. 1, Plenum Press, New York, Chapter 1.

Misra, A., J. Whittenberger, 1987, "Fluoride Salts and Container Materials for Thermal Energy Storage Applications in the Temperature Range 973 to 1400 K," National Aeronautics and Space Administration, NASA Lewis Technical Memorandum 89913.

Olson, L. C., 2009, "Material Corrosion in Molten LiF-NaF-KF Eutectic Salt," Ph.D. dissertation, University of Wisconsin, Madison, WI.

Ozeryanaya, I. N., 1985, "Corrosion of Metals by Molten Salts in Heat-Treatment Processes," Metal Science and Heat Treatment, Vol. 27, (3), pp. 184-188.

Ozeryanaya, I., G. Zalanzinski, M. Smirnov, S. Finkel'shtein, N. Shamanova, 1975, "Corrosion of molybdenum in molten sodium chloride in the presence of carbon," translated from Zashchita Metallov, Vol. 11, No. 1, pp. 66-68. 
Personal Communication 2010: Personal communication, M. Anderson and his group (U. of Wisconsin) with P. Sabharwall (INL), 2010.

Public Law 109-58, 2005, Energy Policy Act of 2005, U.S. Environmental Protection Agency, August 8, 2005.

Sabharwall, P., Ott, L., and Yoder, G., 2004, "Physical Properties and Correlations for the Molten Salt FLIBE and their Implementation in the RELAP5/ATHENA Thermal-Hydraulics Code," Oakridge National Laboratory Report, Nuclear Science and Technology Division, August 2004.

Sridharan, K., 2009, Liquid Salts as Media for Process Heat Transfer from VHTRs: Forced Convective Channel Flow Thermal Hydraulics, Materials, and Coatings, NERI 07-030, NERI Project Review, Panel No. 3, University of Wisconsin, April 11, 2009.

Sridharan, K., M. Anderson, M. Corradini, T. Allen, L. Olson, J. Ambrosek, and D. Ludwig, 2008, Molten Salt Heat Transport Loop: Materials Corrosion and Heat Transfer Phenomena, Final Report, Nuclear Energy Research Initiative (NERI), University of Wisconsin, Madison, WI, July 9, 2008.

Williams, D. F, 2006b, Assessment of Candidate Molten Salt Coolants for the NGNP/NHI Heat Transfer Loop, ORNL/TM-2006-69, Oak Ridge National Laboratory, Oak Ridge, TN, June 2006.

Williams, D. F., L. M. Toth, and K. T. Clarno, 2006a, Assessment of Candidate Molten Salt Coolants for the Advanced High-Temperature Reactor (AHTR), ORNL/TM-2006/12, Oak Ridge National Laboratory, Oak Ridge, TN, March 2006. 